\begin{tabular}{|l|l|l|l|l|l|}
\hline MUNIBE Antropologia-Arkeologia & $n^{\circ} 65$ & $5-24$ & DONOSTIA & 2014 & ISSN 1132-2217 • eISSN 2172-4555 \\
\hline
\end{tabular}

\title{
Reflexiones en torno a la caracterización tecnotipológica del yacimiento de Bañugues (Asturias, España) en el marco del Paleolítico medio del norte de la Península Ibérica
}

\author{
Reflections around the techno-typological characterization of Bañugues site \\ (Asturias, Spain) within the Middle Palaeolithic framework of northern Iberian Peninsula
}

KEY WORDS: Handaxe, Cleaver, Levallois, Mousterian, Cantabrian region.

PALABRAS CLAVES: Bifaz, Hendedor, Levallois, Musteriense, Región Cantábrica.

GAKO-HITZAK: Aurpegibikoa, Arrakalagailua, Levallois, Mousteriarra, Kantaurialdea.

David ÁLVAREZ-ALONSO(1), José Adolfo RODRÍGUEZ ASENSIO(2) y Jesús F. JORDÁ PARDO(3)

\begin{abstract}
Bañugues archaeological site is an example in the studies of Cantabrian first human occupation. This site was found in the sixties, excavated in the seventies, and was a landmark in the Cantabrian Early Palaeolithic research, because it was the first open air site excavated with this chronology. Some notes and papers about the fieldworks developed in 1977 and the surface lithic collection were published in the end of seventies and in the beginning of eighties, but the results of the fieldworks carried out in 1977 in an open area, have been unpublished until the present day. In this paper, we show the complete analysis of the lithic assemblage of Bañugues (1977 \& 1979), as a reflexion about the lithic industries (excavations and private collections). This lithic assemblage was considered as a model for Late Acheulean industries in the Cantabrian region, during a long time. In this framework, its chronostratigraphical position (supposed in OIS 5e) and their technotypological features played an important role. Today, and after making a strong review, we think that this archaeological site should be placed in a Middle Palaeolithic context (maybe Early Middle Palaeolithic). Secondly, from a geomorphological point of view, we must forget any relationship between the sedimentary deposit and an eemian marine terrace. Concerning this topic, we do not accept a relative chronology within OIS 5e; that affirmation is wrong. Actually, Bañugues is placed in a slope deposit (debris flow), which was moved from a higher position to its currently placement

On the other hand, as a result of this study, we also contemplate an historiographical discussion, in which we analyse key concepts to understand this type of archaeological sites: Mousterian of Acheulean Tradition, Vasconian, Southern Acheulean or Upper Cantabrian Acheulean. These names, traditionally used to name mousterian assemblages with cleavers and handaxes or also to talk about open air sites with macro-tools, flake-tools, and Levallois pieces, are the result of the high difficulty to distinguish between Lower Palaeolithic and Middle Palaeolithic.

This issue should be simplified, trying not forget about the connotation of this discussion and all the preexisting periodizations; Middle palaeolithic, in some cases. The scarce number of sites that we know in the Cantabrian region - with chronologies contemporaneous or previous to OIS 5- is a sign of this subject. The basis of the organization of this subject, on which we considerer that in an advanced stage of Ancient Cantabrian Palaeolithic exists a period that we named 'Early Middle Palaeolithic', is exposed in some works (Álvarez Alonso, 2011; 2012; 2014).

Thereby, with this paper we close the debate about the chronocultural attribution of the lithics of Bañuges, which have changed its consideration from the Acheulean to the last definition within Early Middle Palaeolithic. New analysis, new studies and a complete review in this archaeological site, are enough allow us to close the researches began in the seventies of past century.
\end{abstract}

\section{RESUMEN}

El yacimiento de Bañugues es un referente en el estudio de las primeras ocupaciones humanas cantábricas. Descubierto en la década de los años 60, y excavado en los años 70, este yacimiento supuso un hito en el estudio del Paleolítico antiguo cantábrico, al ser el primer yacimiento excavado en un contexto al aire libre. Tras algunas notas y artículos publicados a finales de los años 70 y en los primeros años 80 , referentes a las intervenciones del año 1977 y a las colecciones de superficie, los resultados de la excavación en extensión efectuada en 1979 han permanecido inéditos hasta la actualidad. En este trabajo se presenta el análisis completo del conjunto lítico recuperado en Bañugues (1977 y 1979), así como una reflexión sobre el conjunto industrial y las colecciones existentes. De este modo cerramos el debate sobre la adscripción cronocultural del conjunto lítico, que ha oscilado entre su asignación al Achelense y su definitivo encuadre en el Paleolítico medio. Nuevos análisis, nuevos estudios y una completa revisión de este sitio arqueológico, sirven para cerrar las investigaciones iniciadas en la década de los años 70 del pasado siglo.

\footnotetext{
(1) Departamento de Prehistoria y Arqueología, UNED-Asturias. Avda. Jardín Botánico 1345 (Calle interior) 33203 Gijón, Asturias. dalvarez@gijon.uned.es (2) Área de Prehistoria y Arqueología, Universidad de Oviedo. c/ Teniente Alfonso Martínez, s/n, 30011, Oviedo. adolfo@uniovi.es (3) Laboratorio de Estudios Paleolíticos / Departamento de Prehistoria y Arqueología, UNED. Ciudad Universitaria, Po Senda del Rey 7, 28040, Madrid. jjorda@geo.uned.es
} 


\section{LABURPENA}

Bañugueseko aztarnategia Kantaurialdeko lehen giza okupazioen ikerketan erreferentea da. 60ko hamarkadan aurkitu eta 70eko hamarkadan hondeatu zuten aztarnategi hau. Kantaurialdeko antzinako Paleolitikoaren azterketan erreferentzia bihurtu zen, aire zabalean hondeatutako lehen aztarnategia izan zelako. 70eko hamarkadaren amaieran eta 80ko hamarkadaren hasieran 1977. urteko esku-hartzeen eta gainazaleko bildumen inguruan argitaratutako ohar eta artikulu batzuen ondoren, hedapeneko hondeaketako emaitzak argitaratu gabe egon dira gaur egunera arte. Lan honetan azaltzen dira Bañuguesen (1977 eta 1979 urteak) berreskuratutako multzo litikoaren azterketa osoa, eta multzo industrialari eta bildumei buruzko hausnarketa. Horren bidez, multzo litikoaren atxikipen kronokulturalari buruzko eztabaida amaitutzat joko dugu; izan ere, Acheul Aldiari esleitu eta, behin betikoz, Erdiko Paleolitikoan txertatzearen artekoa izan da eztabaida. Gune arkeologiko horren azterketa berriek, ikerketa berriek eta berrikusketa osoak aurreko mendeko 70eko hamarkadan hasitako ikerketak ixteko balio izan dute.

\section{1.- INTRODUCCIÓN}

El yacimiento de Bañugues está situado en el centro del litoral asturiano, al este del Cabo Peñas, en una ensenada formada por un valle abierto en la línea de costa (Fig. 1). El yacimiento se localiza dentro de un depósito de ladera actualmente ubicado al borde de un antiguo estuario que se abre al mar por una boca de $400 \mathrm{~m}$ de anchura. Esta disposición ha condicionado que el depósito sedimentario haya sufrido la acción erosiva del mar durante el Holoceno, erosión que prosigue en la actualidad. Contiene una secuencia arqueológica que comprende niveles del Paleolítico medio, en la parte inferior, y materiales asturienses en el horizonte erosivo que se asocia con la transgresión flandriense.
Bañugues fue el primer yacimiento del Paleolítico antiguo excavado en Asturias, y uno de los pioneros en la Región Cantábrica, ya que se trata de la primera excavación de un yacimiento al aire libre de esta cronología en toda la región. Por esta razón ha sido, desde hace décadas, una de las referencias más citadas e ineludibles cuando se aborda la temática del Paleolítico antiguo asturiano en particular, y cantábrico en general (RODRíGUEZ ASENSIO y ARRIZABALAGA, 2004; ÁLVAREZ ALONSO, 2010b). Este yacimiento fue descubierto por Domingo Caramés y Joaquín Manzanares en 1961 (PÉREZ PÉREZ, 1975), instante a partir del cual empezó a ser fruto de intensas y constantes recogidas superficiales de material en sus inmediaciones. Estos hallazgos
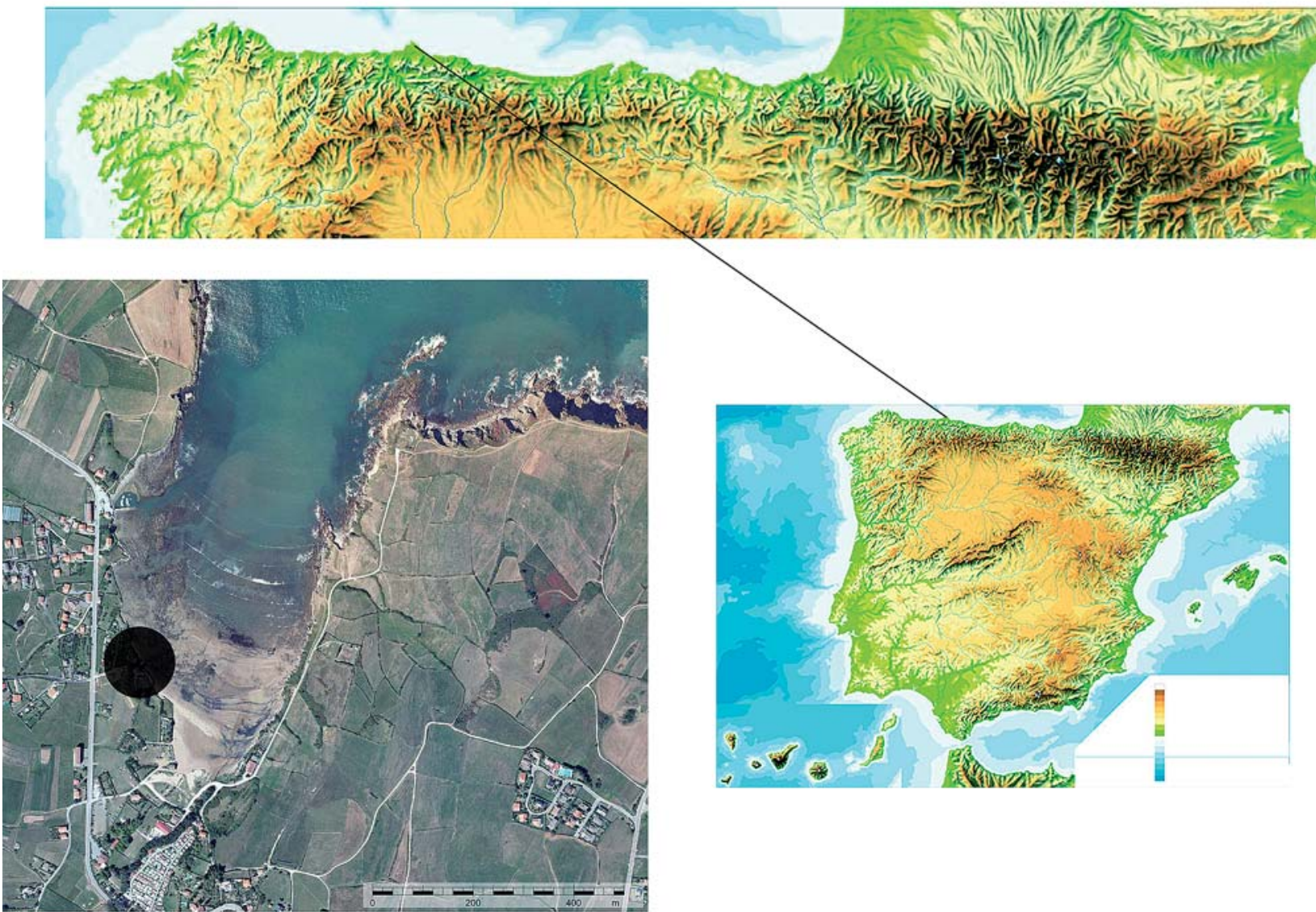

Fig. 1. Mapa de situación / Location map. 
fueron atribuidos sucesivamente al Abbevillense (JORDÁ, 1967), Paleolítico inferior (GONZÁLEZ FERNÁNDEZ, 1968), Abbevillense, Achelense y Asturiense (JORDÁ CERDÁ, 1975), del Abbevillense al Musteriense de tradición achelense (PÉREZ PÉREZ, 1975), Achelense superior final (JORDÁ CERDÁ, 1977: 55) y del Achelense superior evolucionado al Musteriense de tradición achelense (RODRÍGUEZ ASENSIO 1978b).

A partir de 1977, uno de nosotros (J.A.R.A.) realizó investigaciones en el yacimiento, iniciando de este modo la arqueología ínfero-paleolítica en Asturias en época moderna (RODRÍGUEZ ASENSIO, 1978a, 1978b, 1980, 1983), constituyendo estas excavaciones a su vez, un hito en la Prehistoria asturiana. Las intervenciones arqueológicas se iniciaron en 1977 con una campaña de sondeos arqueológicos que se completó con una excavación en extensión en 1979. Con posterioridad a la excavación, el yacimiento ha ido siendo erosionado progresivamente por el mar, dejando a la luz su contenido arqueológico, circunstancia que ha posibilitado que el horizonte paleolítico se haya ido perdiendo con el paso de los años (RODRÍGUEZ ASENSIO, 1983). Actualmente, no queda apenas resto alguno de material arqueológico en superficie en la ensenada de Bañugues, más allá de alguna pieza aislada que se desprende del talud donde se encuentra lo que queda del yacimiento.

En este trabajo nos centraremos en realizar un análisis de la industria lítica, incluyendo los datos inéditos de la excavación de 1979, a la luz de las nuevas investigaciones sobre el yacimiento de Bañugues y de la revisión del contexto general del Paleolítico antiguo cantábrico (ÁLVAREZ ALONSO, 2010a, 2012, 2014; ARRIZABALAGA y RÍOS, 2012).

\section{2.- CONTEXTO GEOLÓGICO Y ESTRATIGRAFÍA DEL YACIMIENTO}

El sustrato geológico de la ensenada de Bañugues está compuesto por calizas, dolomías y limolitas de la formación Rañeces (Devónico inferior), aunque también en algunas zonas afloran unas arcillas amarillentas y margas arcillosas, atribuidas por G. Flor al Cretácico inferior (Aptense). Sobre este sustrato se asientan los depósitos cuaternarios, constituidos por brechas, arenas, limos y arcillas (RODRÍGUEZ ASENSIO y FLOR, 1980).

En un primer momento, Bañugues y su depósito geológico fue descrito por N. Llopis Lladó como una serie de depósitos aluviales y coluvio-aluviales que rellenan una gran vaguada excavada sobre materiales devónicos (calizas de Nieva y pizarras) (LLOPIS, 1962), formando a su vez una terraza a $+2,5 / 3$ m, en la cual se hallan los materiales paleolíticos (RODRÍGUEZ ASENSIO y FLOR, 1983; HOYOS, 1987, 1989).

Sobre la estratigrafía y formación del yacimiento se ha debatido bastante, existiendo diversas interpretaciones desde la primera valoración realizada por F. Jordá, quien considera que las alteraciones por solifluxión y crio- turbación existentes en el nivel B-6 (nivel VIII) podrían ser datadas en el Riss III, del mismo modo que sitúa el nivel B-3a (nivel IV) en la fase eólica del Würm I, por lo que onsidera que el yacimiento debería encuadrarse en el interglaciar Riss-Würm (JORDÁ CERDÁ, 1977: 53). Así, los datos aportados por la sedimentología indujeron a pensar en la formación del depósito arqueológico durante un momento frío, considerando éste relacionado con los fenómenos de solifluxión basales en concordancia con una retirada del mar del estuario, lo que pudo haberse producido hacia el final del interglaciar Riss-Würm o al inicio del Würm I (RODRÍGUEZ ASENSIO, 1990). Por esta circunstancia el depósito paleolítico quedó encuadrado en el OIS 5. Por su parte, M. Hoyos reafirma esta hipótesis planteando que la terraza marina de Bañugues $(+2 m)$ se corresponde con el último interglaciar (HOYOS, 1987).

Durante la excavación, los horizontes fértiles se dividieron en dos, el nivel V y el VII, constituidos por sendas brechas muy similares entre sí, formadas por cantos de pizarra y cuarcita y con matriz de limos arenosos, que en algunos puntos llegan a fundirse en un solo nivel (RODRÍGUEZ ASENSIO, 1980). En realidad, se trata de un único horizonte arqueológico que corresponde a sendas digitaciones laterales de un mismo paquete de brechas, puesto que su procedencia se debe a un deslizamiento de materiales desde una posición más elevada, en un movimiento a favor de la ladera de tipo debris flow al que se le ha atribuido una génesis por solifluxión (HOYOS, 1976; RODRÍGUEZ ASENSIO y FLOR, 1980).

En la actualidad, la secuencia visible (Fig. 2) arranca sobre una alternancia de dolomías y limolitas de la formación Rañeces (Devónico inferior), sobre cuya alteración aparece un depósito de brechas de color marrón claro (actual nivel B.5) con clastos angulosos de las dolomías del sustrato junto con otros de naturaleza alóctona y matriz de arenas de cuarzo. Hacia el techo, esta brecha pasa a un depósito de arenas de cuarzo (actual nivel B.4) y color marrón claro-amarillo, muy rico a techo en nódulos milimétricos de óxidos de Mn. Este nivel se encuentra erosionado y sobre la cicatriz se disponen limos y arenas (actual nivel B.3) de color rojizo con nódulos milimétricos de óxidos de Mn en su tramo basal, que hacia arriba pasan a arenas amarillas (actual nivel B.2), ligeramente marrones a techo, sobre las que se dispone un suelo orgánico de color marrón oscuro a negro (actual nivel B.1). El emplazamiento de estos depósitos es compatible con los procesos sedimentarios indicados por anteriores autores: por un lado la solifluxión o debris flow para los dos niveles basales de la secuencia (B.5 y B.4), y una sedimentación marina para los dos niveles superiores (B.3 y B.2) (JORDÁ CERDÁ, 1977; HOYOS, 1976; RODRÍGUEZ ASENSIO y FLOR, 1980), teniendo en cuenta que el nivel superficial (B.1), corresponde al suelo edáfico actual. Además, la secuencia permite ver rasgos correspondientes a, al menos, dos paleosuelos: uno, más antiguo, decapitado entre B.4 y B.3, y otro en los niveles superiores, desarrollado con anterioridad al suelo actual. 


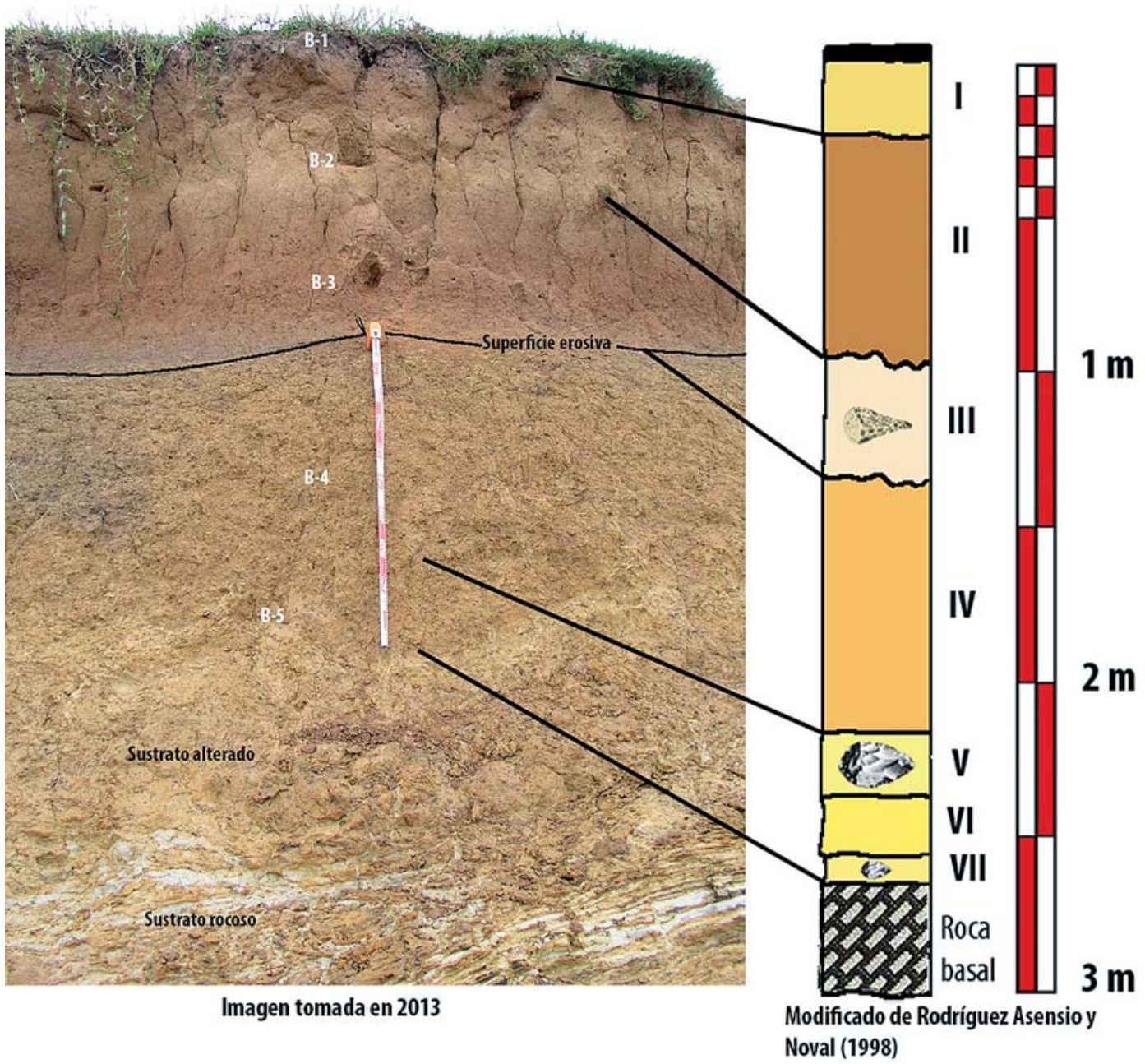

Fig. 2. Estratigrafía /

Stratigraphy.

\section{3.- MATERIALES: LA INDUSTRIA LÍTICA DE BAÑUGUES}

El conjunto lítico de Bañugues lo forman un total de 379 piezas (Fig. 3), de las que 130 proceden de la campaña de 1977 (RODRÍGUEZ ASENSIO, 1978a, 1978b, 1980, 1983; ÁLVAREZ ALONSO, 2004, 2010a) y 249 de la campaña de $1979{ }^{1}$, de las cuales el $82,84 \%$ son de cuarcita, el 13,19\% de sílex y el 3,97\% corresponde a otras materias (cuarzo, arenisca y nódulos de Fe). En esta división por materias primas es necesario hacer una matización, ya que el sílex está representado en su totalidad por productos de talla (lascas y restos de talla), mientras que en el grupo de la cuarcita además de estos hay 29 cantos rodados (percutores, cantos tallados y núcleos) que suponen el 7,65\% de la cuarcita.

\begin{tabular}{|c|c|c|c|c|}
\hline CATEGORÍAS & & 1979 & 1977 & $\%$ \\
\hline Núcleos & & 18 & 6 & 6,3 \\
\hline Lascas & & 169 & 91 & 68,6 \\
\hline Restos de Talla & & 16 & 16 & 8,44 \\
\hline $\begin{array}{l}\text { Elementos } \\
\text { retocados }\end{array}$ & & 26 & 11 & 9,76 \\
\hline Hendedores & & 1 & 2 & 0,79 \\
\hline Bifaces & & 1 & 0 & 0,26 \\
\hline Cantos Trabajado & & 4 & 1 & 1,31 \\
\hline Masivos & & 2 & 0 & 0,52 \\
\hline Percutores & & 12 & 3 & 3,95 \\
\hline Total & 379 & 249 & 130 & 100 \\
\hline
\end{tabular}

Fig. 3. Tabla de materiales líticos procedentes de la excavación (campañas 1977 y 1979)/ Lithic materials of the excavation (1977 \& 1979 seasons). 


\subsection{Cadena Operativa Formativa}

Los bifaces y hendedores están muy poco representados ya que tan sólo contamos con cuatro piezas, dos hendedores del tipo 0 y II de J. Tixier (1956) (fig. 4), ambos en cuarcita, una pieza de cuarcita afín a hendedor y un protobifaz, también sobre cuarcita. Mientras los hendedores resultan ser piezas bastante típicas, el otro elemento de macro-utillaje bifacial, al que creemos más apropiado denominar protobifaz, resulta ser un elemento configurado que, aún presentando cierta afinidad morfológica con los bifaces, no goza de las características y atributos que definen este tipo de elementos de façonage (simetría y clara configuración bifacial con el objetivo de obtener un macroútil con filos convergentes).

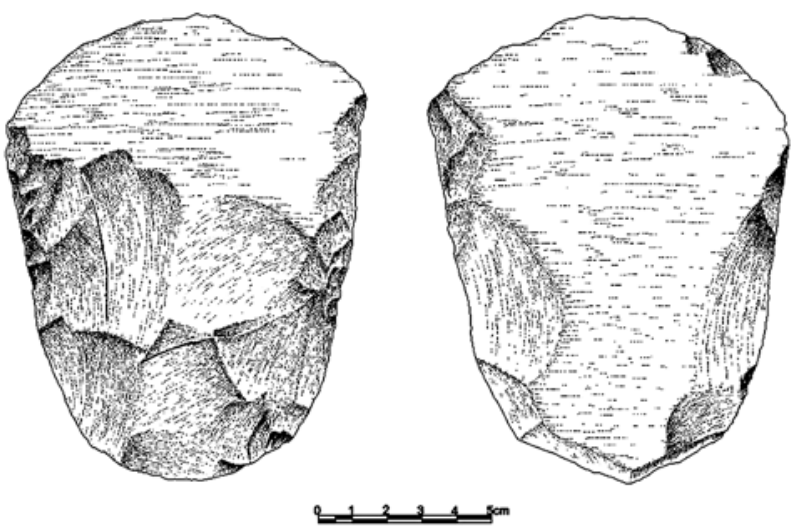

Fig. 4. Hendedor procedente de la campaña de excavación de 1977 / Cleaver found in 1977 excavation season.

Esta Cadena Operativa no parece constituir uno de los objetivos principales dentro de las estrategias de talla y fabricación de utillaje documentadas en Bañugues. Por otra parte, sí destacan otro tipo de elementos masivos, representados por los cantos trabajados (Fig. 5) y lo que denominamos 'masivos retocados'2 (7 piezas en total), definidos como piezas en las que se ha obtenido un filo simple a partir de grandes extracciones (CT) o mediante el retoque de soportes masivos que no son, ni cantos rodados ni grandes lascas (masivos retocados). Si bien no podemos hablar de elementos en los que media una configuración, y por lo tanto una concepción morfológica mediante façonage, sí se trata de verdaderos elementos de macro-utillaje que tal vez puedan responder mejor a una estrategia de inmediatez en su fabricación y uso.

En Bañugues, además existe una importante y numerosa colección de superficie, dividida en varios lotes pertenecientes a particulares, compuesta en su mayor parte por piezas de macro-utillaje. Entre estos materiales de las colecciones privadas se llevó a cabo un detallado estudio ${ }^{3}$ sobre un total de 774 piezas. Así, se documentaron 27 bi-

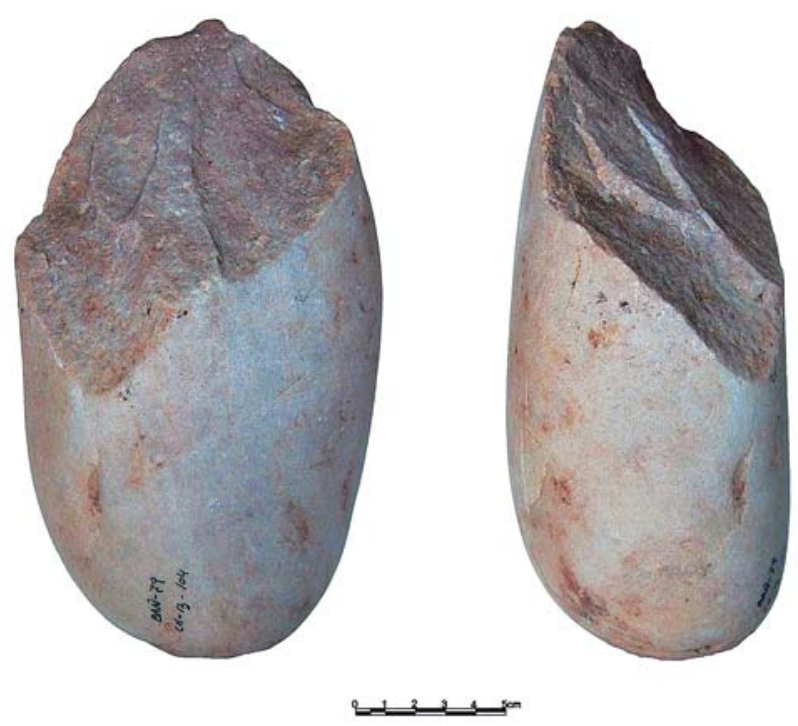

Fig. 5. Canto trabajado unifacial. Elemento de macroutillaje / Chopper. Macro-tool piece.

faces, debiendo destacar que 20 de ellos son de tipo espeso ( 7 amigdaloides, 10 amigdaloides cortos y 3 protolimandes) mientras que sólo hay 3 bifaces planos (1 limande y 2 discoides) además de 4 piezas fracturadas (RODRÍGUEZ ASENSIO y FLOR, 1980). De estas piezas, el $40 \%$ tienen la base reservada en su totalidad, mientras que el 18,51\% sólo la tienen parcialmente reservada, destacando que todos ellos entraron en la banda IV (BORDES, 1961). Obviamente estas colecciones proceden de una selección visual del material y están fuertemente sesgadas. A pesar de ello, podemos resaltar el dato que hace alusión a la abundancia de bifaces de tipo espeso, con bases reservadas.

Por lo que respecta a los hendedores procedentes de recogidas en superficie, únicamente se analizaron 13 (11 del tipo 2 y 2 del tipo 1), predominando los de tipo espeso. Por su parte, los picos triedros apenas están representados entre el material de superficie, con respecto a los anteriores grupos tipológicos, ya que sólo se ha descrito una pieza de estas características (RODRÍGUEZ ASENSIO y FLOR, 1980).

\subsubsection{Los cantos tallados de Bañugues}

Durante la excavación y el estudio de las colecciones de superficie realizado por uno de nosotros (RODRíGUEZ ASENSIO, 1980, 1983; RODRÍGUEZ ASENSIO y FLOR, 1980) se constató un elevado número de cantos tallados, que supone el conjunto de útiles más representados en la ensenada. De entre todos estos "cantos trabajados", presentes en las colecciones realizadas a expensas del material de superficie, se pudo comprobar

\footnotetext{
${ }^{2}$ A este tipo de piezas ya nos hemos referido con anterioridad en otros trabajos (ÁLVAREZ-ALONSO y ARRIZABALAGA, 2012)

${ }^{3}$ Realizado por J. A. Rodríguez Asensio durante la realización de su Tesis Doctoral.
} 
que muchos de ellos encajaban con materiales de fortuna, cantos con extracciones aleatorias y limitadas (cantos unifaciales simples) que estarían en la línea de la dinámica natural que se produce en contextos de playas fluviales o marinas, en las que el golpeo y fractura de los materiales es una circunstancia habitual. Además se da la circunstancia de que en Bañugues está documentado un horizonte arqueológico con material asturiense, del cual pudieran también proceder. También en la ensenada desemboca el río La Cabaña, que aporta numeroso material rodado a la playa. En líneas generales, y con respecto a los cantos hallados en superficie, es difícil encuadrarlos en un horizonte cronocultural concreto, además de la dificultad que entraña separar lo que realmente está tallado de los cantos fortuitos.

A pesar de ello y teniendo en cuenta estas circunstancias, fueron estudiados 252 cantos (el 32,55\% de los materiales revisados, lo cual da una idea de su importancia en estas colecciones), todos procedentes de las colecciones particulares de J. González y Fernández Valles y A. Miyar, resultando 74 unifaciales, 125 bifaciales y 53 esferoides. Debemos destacar que el análisis de estas piezas mostró la presencia de un módulo de canto aplanado, preferente en los tipos unifaciales y bifaciales, mientras que en los de tipo esferoide los cantos matriz tienden a ser globulares (RODRÍGUEZ ASENSIO y FLOR, 1980). Aquí nos hemos planteado si pudiera haber existido una selección intencional, y por lo tanto una diferencia funcional entre los cantos presentes, o esta diferenciación simplemente responde a una consecuencia fortuita. Tras el estudio efectuado a la colección hallada en contexto estratigráfico, podemos arrojar más luz sobre esta circunstancia y apuntar la posible existencia de una planificación en el uso y configuración de los cantos que no deben ser encuadrados, por lo tanto, bajo una única e idéntica consideración de "cantos trabajados" (Fig. 6). A resultas de esto, hemos dividido estos cantos en tres grupos: percutores, núcleos y útiles (elementos de macro-utillaje). En este apartado únicamente nos referiremos a los percutores y a los cantos tallados como elementos de macro-utillaje.

En la colección procedente de la excavación arqueológica, debemos destacar el elevado número de percutores presentes; en total son 15 los cantos que han sido clasificados en este grupo. En algunos casos, y debido a su uso, se han fracturado accidentalmente por lo que estos percutores han adquirido una morfología similar a la de cantos tallados ${ }^{4}$. Con respecto a estas piezas, hemos observado tres casos diferentes: (1) los percutores no fracturados, con numerosos estigmas de impacto en sus extremos; (2) los percutores que se han fracturado como consecuencia de su uso; y en último lugar (3) los percutores que aún estando fracturados (o tallados), han seguido siendo usados en la parte que ofrece un filo (Fig. 7). En consecuencia nos cabe la duda de si la talla de cantos para su posterior uso como percutores es una estrategia específica desarrollada en este yacimiento, o por el contrario se trata de un aprovechamiento no premeditado.

La presencia en el conjunto de 'cantos tallados unifaciales' con estigmas de percusión en sus filos y con uso como percutor en el lado opuesto a este, nos hace plantearnos la siguiente hipótesis:

¿Podría haber sido una estrategia de talla la preparación de percutores para actividades específicas y diversas? Esta hipótesis, que deberíamos constatar con una aproximación experimental, parte de la idea de que algunos cantos de tipo aplanado hayan sido seleccionados intencionalmente para usos concretos. Este uso radicaría en la combinación de dos tipos de percusión en una misma pieza, es decir, utilizando ambos extremos distales del canto con fines distintos, a partir de la preparación espe-
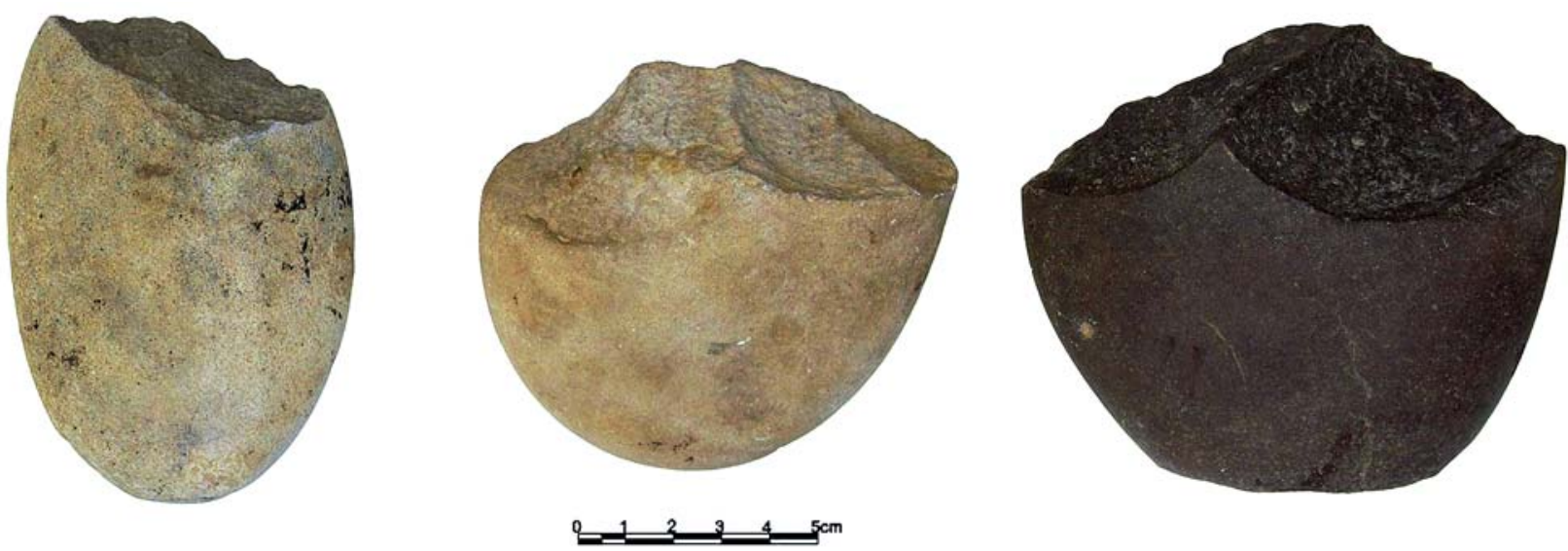

Fig. 6. Distintos tipos de 'cantos trabajados' / Different types of 'Chopping tools.

${ }^{4}$ Piezas que presentan en uno o ambos extremos, estigmas de percusión, microoquedades y lascados (negativos) cuyo punto de impacto coincide con estas 'zonas activas', que llevan a considerar estos lascados como una consecuencia del uso de los cantos como percutores y no como lascados intencionados. 

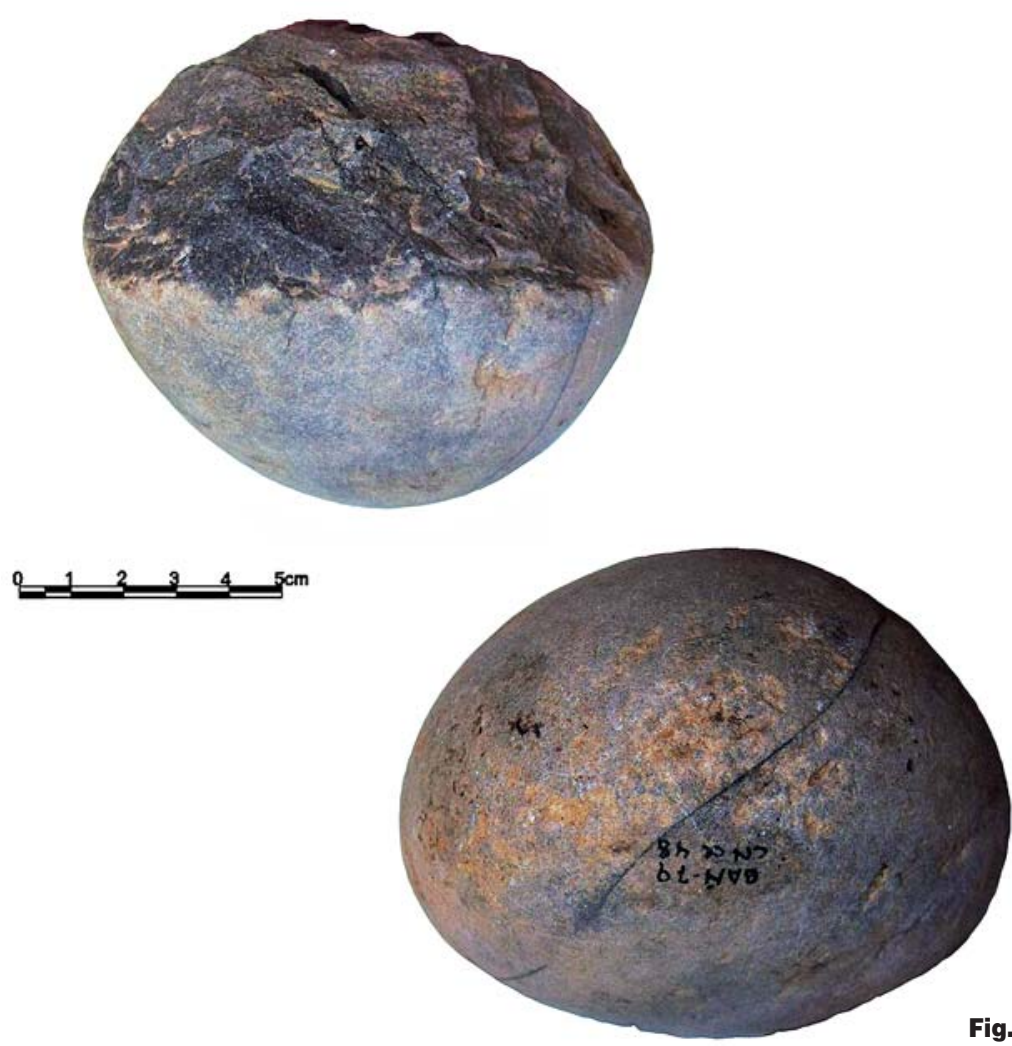

Fig. 7. Percutor / Hammer.

cífica de uno de ellos. De este modo un extremo sería utilizado como percutor masivo, mientras que en lado opuesto se habrían realizado 5 varias extracciones para obtener una arista que ofrezca puntos de percusión más definidos y fáciles de controlar, con el fin de ser usados en una fase de talla más controlada; tal vez como retocadores o incluso para su utilización sobre material orgánico (p.ej. fracturación de diáfisis). Serían pues ¿percutores mixtos? con dos zonas activas complementarias para labores de talla diferentes dentro del proceso de elaboración de útiles; no podemos asegurarlo. La justificación de este tipo de percutores podría estar en combinar la contundencia necesaria en las primeras extracciones (fases de descortezado o debitado) con una mayor control de los golpes en labores de retoque, façonage o incluso en la extracción de determinados soportes como los derivados de la talla Levallois; pero no excluimos que el uso de estas herramientas haya podido ser dentro de una Cadena Operativa no lítica, y sí dentro de un aprovechamiento de material orgánico (trabajo en madera, fractura de huesos largos o carcasas de animales, etc...) que posiblemente tuvieron lugar en el yacimiento.

Por otra parte, en el conjunto lítico de Bañugues hay un número elevado de cantos tallados que al margen de los percutores, hemos considerado que se podrían clasificar como núcleos unifaciales sobre plataforma cortical -
NUPC-, así como un número más reducido, que se pueden clasificar dentro de una definición más clásica para este tipo de elementos, y por lo tanto los consideraríamos como cantos trabajados, auténticos elementos de macro-utillaje.

No debemos olvidar que la presencia elevada de cantos tallados en un conjunto lítico nada tiene que ver con cuestiones cronológicas, y mucho menos con aspectos evolutivos de las industrias líticas desde un punto de vista tecnológico. Debemos verlo como una cuestión más funcional, así como un aspecto derivado del tipo de materia prima presente en el entorno que condiciona, sin duda, los métodos de talla planteados en el yacimiento. El caso de El Aculadero (SANTONJA y PÉREZ, 2010b) resulta de especial interés a la hora de valorar esta circunstancia. Con un conjunto abundante de cantos tallados, este yacimiento fue considerado en un principio perteneciente a una fase antigua del Paleolítico inferior arcaico, apoyándose en la edad geológica del sustrato basal y en la ausencia de elementos achelenses. Tras exhaustivas revisiones cronoestratigráficas y de la industria lítica, se llegó a la conclusión de que se trata de un conjunto perteneciente al Paleolítico medio, situado en el OIS 5, en el que destaca el uso masivo de cantos para realizar núcleos (varios de ellos levallois y discoides, así como distintos útiles). Por esta razón, no podemos considerar el volumen de cantos tallados de un conjunto lítico como un rasgo definitorio de su carácter cul-

${ }^{5}$ Repetimos nuestra duda acerca de su intencionalidad o su aprovechamiento fortuito como consecuencia de la fractura de los percutores. 
tural o cronológico, ya que por cantos tallados podemos interpretar también algunos percutores y núcleos, como hemos comprobado en Bañugues, y no sólo a los verdaderos elementos de macro-utillaje (chopper y chopping tools). En definitiva, tomar este elemento como marcador de un supuesto arcaísmo del conjunto lítico e interpretar esta circunstancia como un argumento a favor de una cronología ínfero-paleolítica, sería totalmente erróneo.

\subsection{Cadena Operativa de Debitado}

Compuesta por 316 piezas, de las que 260 son lascas (84,61\% cuarcita; 13,46\% sílex; 1,92\% otros) 24 son núcleos y 32 son restos de talla (Fig. 8).

\begin{tabular}{|lccccccc|}
\hline & & & & \multicolumn{3}{|c|}{ Materia prima } \\
\cline { 3 - 7 } TIPO & 1977 & 1979 & $\%$ & cuarcita & sílex & otros \\
\hline Primario & 0 & 3 & 1.15 & 2 & 1 & 0 \\
Secundario & 18 & 47 & 25 & 55 & 10 & 0 \\
Sin córtex & 73 & 119 & 73.84 & 163 & 24 & 5 \\
\hline \multicolumn{1}{c}{ Total } & $\mathbf{9 1}$ & $\mathbf{1 6 9}$ & $\mathbf{1 0 0}$ & $\mathbf{2 2 0}$ & $\mathbf{3 5}$ & $\mathbf{5}$ \\
\hline
\end{tabular}

Fig. 8. Grado de corticalidad (Lascas) / Cortex degree (Flakes).

La presencia de lascas de desbastado primario es testimonial $(n=3)$, ya que la mayor parte de estos soportes no presentan superficies ni restos corticales $(n=192)$, y de entre las lascas que presentan algún resto cortical $(n=65)$, 35 presentan menos de 1/3 de córtex. En líneas generales los restos corticales se distribuyen de manera homogénea por las zonas distal, proximal y lateral de las lascas, correspondiendo con la explotación de matrices que parecen estar ya descortezadas o en un grado de preparación elevado. Esta circunstancia nos indicaría la existencia de distintas fases de talla llevadas a cabo en espacios diferentes, siendo el conjunto procedente de la excavación, coherente con una actividad secundaria o final dentro del proceso de talla. Aceptando esta situación como derivada de una funcionalidad espacial, habría existido un lugar de captación, no muy lejano, en el que seguramente se habría llevado a cabo una primera fase de debitado, orientada a eliminar materia cortical y aligerar las matrices para su transporte. En el cauce del cercano río La Cabaña hay numerosos cantos rodados de características similares a los hallados en el yacimiento, por lo que potencialmente podría ser un lugar de captación de materia prima.

Profundizando en la gestión de la talla lítica, debemos fijarnos en los talones identificados en las lascas, donde predominan los lisos $(58,18 \%)$ seguidos de los corticales $(18,96 \%)$, los facetados $(15,08 \%)$ y los diedros $(7,75 \%)$. A la hora de analizar las plataformas de percusión preparadas, hemos obtenido el siguiente índice de facetado (IF) del $22,84 \%$ y un índice de facetado estricto (IFs) del $15,08 \%$, destacando en este conjunto lítico un elevado número de superficies de explotación jerarquizadas, lo cual nos está apuntando la existencia de métodos de reducción complejos pero también variados, como veremos más adelante. Si sólo atendemos a las lascas que no presentan restos de córtex en su cara dorsal, los índices se convierten en (IF) $26,51 \%$ y (IFs) $18,23 \%$.

Cuando analizamos los métodos de talla mediante la observación de las superficies dorsales de las lascas, así como por el tipo de extracciones que éstas presentan en su anverso, vemos que predominan los esquemas centrípetos y unipolares, mientras que no se registran evidencias de bipolaridad en ninguna de las lascas. Por otra parte, los ángulos de percusión identificados a partir de la relación angular formada por el plano del talón y el plano que genera la cara ventral de las lascas (Fig. 9), se sitúa mayoritariamente por debajo de $110^{\circ}$, habiendo una notable representación de los ángulos inferiores a $100^{\circ}$. Esta distribución está alejada de los ángulos predominantes en conjuntos achelenses, que si bien se sitúan en parámetros similares en lo que respecta al rango situado entre los $100^{\circ}$ y los $110^{\circ}$, presentarían una mayor representación de ángulos superiores a $110^{\circ}$ e incluso a $120^{\circ}$

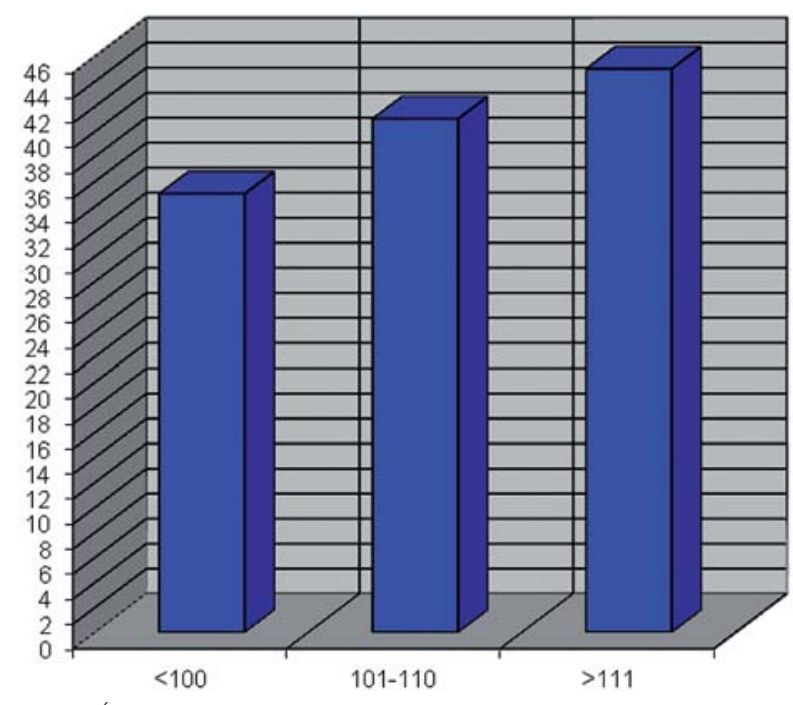

Fig. 9. Ángulos de percusión identificados / Percusión angles identified.

Entre el conjunto lítico también se han identificado un número bastante representativo de productos que provienen del método de talla Levallois, o incluso otros como puede ser el discoide unifacial (Fig. 11) -aceptando la gran variedad de definiciones a las que ha dado lugar recientemente la redefinición del método discoide (SLIMAK, 2003; TERRADAS, 2003)-. Esta circunstancia, unida a las relaciones angulares presentes y los demás atributos observados en los productos de talla, como la organización de los anversos y los talones, nos indican la presencia de métodos de reducción de tipo Levallois y discoide, que parecen aproximar el conjunto de Bañugues hacia el Paleolítico medio. Por otra parte, y tomando un criterio tipologista que nos permita acercarnos a la bibliografía de conjuntos analizados bajo estas perspectivas, en este conjunto se ha obtenido un índice Levallois (IL) del 21,28\%, y un índice Levallois tipológico (IL typ) del 58,8\% que al menos nos permite comparar nuestros datos con otros de 

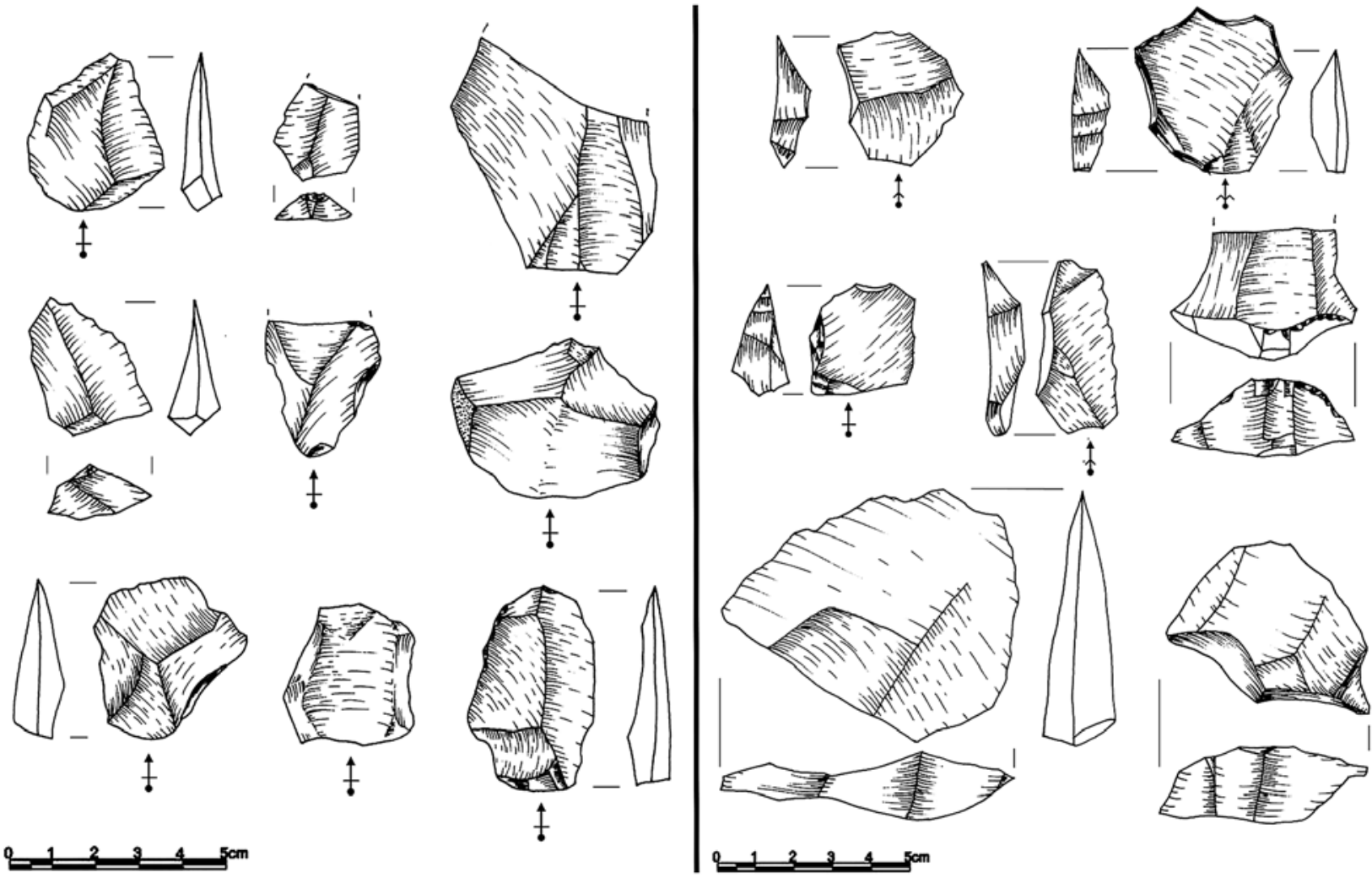

Fig. 10. Lascas discoides y levallois (iz.); productos de acondicionamiento (dcha.) / Discoid and levallois flakes (left); preparation products (right).

similares características en los que han sido aplicados estos mismos parámetros de la tipología de Bordes (1961).

Es este el caso del yacimiento al aire libre de La Plane (Dordoña, Francia), clasificado por A. Turq como Musteriense de Tradición Achelense (TURQ, 2000) cuyos índices se aproximan bastante a los obtenidos en Bañugues. Otros ejemplos son algunos yacimientos de Haut-Agenais (Dordoña) mencionados también por A. Turq (2000) como La Burlade, Ségala, La Lizonne o Les Ardailloux, todos ellos conjuntos realizados en sílex (TURQ, 2000) (Fig. 12).

Por otro lado, en la Región Cantábrica, tenemos el ejemplo del nivel 24 de la cueva de El Castillo englobado dentro del Paleolítico medio antiguo y con una cronología superior a $90 \mathrm{ka}$, donde por ejemplo estos índices son inferiores a los obtenidos en Bañugues (CABRERA, 1984; ÁLVAREZ ALONSO, 2012; 2014). Siguiendo con el caso cantábrico, si cuantificamos el número de piezas levallois de Lezetxiki VI, perteneciente al límite entre el Pleistoceno medio y superior, el porcentaje se sitúa en el 12, 5\% sobre el total de piezas de ese nivel (ÁLVAREZ ALONSO y ARRIZABALAGA, 2012); mientras que en Bañugues llega al $13,94 \%$ ( $n=53$ piezas) sobre el total de la muestra. Sin duda, la proporción de elementos Levallois en Bañugues es superior con respecto a Lezetxiki VI y en cambio a Bañugues se le ha venido considerando tradicionalmente como un yacimiento encuadrado en el Achelense superior final y a Lezetxiki como un conjunto musteriense sin dis- cusión. Por nuestra parte, consideramos que en ambos casos se trata de conjuntos pertenecientes al Paleolítico medio, un Paleolítico medio en el que en varios ocasiones hay pervivencia de elementos de macroutillaje, presentes también en las etapas achelenses, pero que se manifiestan de manera diferente a lo largo de la región en función del tipo de asentamiento, (al aire libre o en cueva, tal vez con funcionalidades diferentes) o del tipo de materia prima presente en el entorno (ÁLVAREZ ALONSO y ARRIZABALAGA, 2012). El tipo y calidad de la materia prima (nódulos de sílex o cantos de cuarcita) que se distribuyen de manera diferente a lo largo de la Región Cantábrica, puede ser uno de los factores más importantes a la hora de caracterizar las industrias presentes de Este a Oeste, que sin duda no hacen más que adaptarse técnicamente al tipo de materiales existentes en cada zona.

\subsubsection{Núcleos y métodos de talla}

El estudio de los métodos y técnicas de talla identificadas debe completarse con el análisis de los productos antes presentado, así como principalmente de los núcleos, que en Bañugues ascienden a un total de 24. Dentro del conjunto hemos identificado 4 tipos distintos de explotación a partir de los núcleos presentes, que utilizan como matrices tanto lascas como cantos: en primer lugar el método discoide (algunos podrían ser levallois agotados); en segundo lugar el método Levallois (identi- 

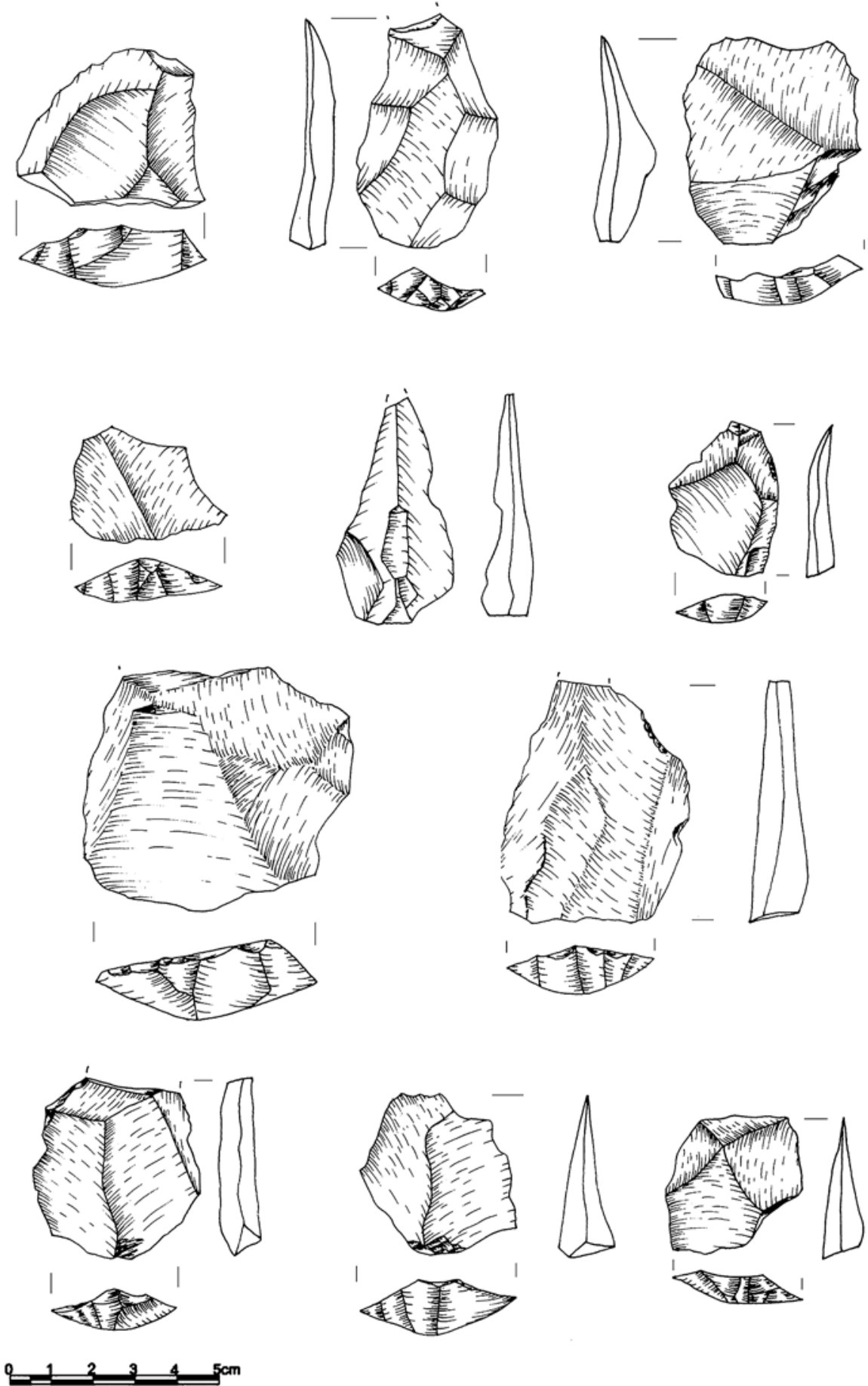

Fig. 11. Lascas levallois / Levallois flakes.

\begin{tabular}{|c|c|c|c|c|c|c|c|}
\hline$\%$ & La Plane & La Burlade & Séaala & La Lizonne & Les Ardailloux & El Castillo 24 & Bañuques \\
\hline IF & 35 & 38 & 29.9 & 32.1 & 28.6 & 14.95 & 22.84 \\
\hline IF.s & 23 & 26 & 18.2 & 23.1 & 24.3 & 11.21 & 15.08 \\
\hline IL & 22 & 37.7 & 3.4 & 29,5 & 11.7 & & 21.28 \\
\hline IL. Tvp & 65 & & & & & & 58.8 \\
\hline Cronol. & MTA & MTA & MTA & MTA & MTA & PMA & \\
\hline
\end{tabular}

Fig. 12. Indices de facetado y levallois de distintos yacimientos franceses y cantábricos. MTA (Musteriense de Tradición Achelense); PMA

(Paleolítico Medio Antiguo) /

Faceted and levallois index from different French and Cantabrian sites. MAT (Mousterian of Acheulean Tradition); EMP (Early Middle Palaeolithic) 
ficado tanto en productos como en núcleos); en tercer lugar algunos núcleos de tipo ortogonal y aspecto similar a un esferoide, que podemos clasificar como núcleos SSDA (Sistema de Superficie Debitage Alterno); y en cuarto lugar los núcleos NUPC.

Los métodos discoide y levallois, son los más habituales, utilizando grandes lascas o fragmentos de cantos. Cabe la posibilidad de que algunos productos puedan confundirse entre el método Levallois recurrente y estrategias discoides más complejas (PERESANI, 2003; SLIMAK, 2003; TERRADAS, 2003), aunque en cualquier caso se trataría de métodos jerarquizados para la extracción de lascas, habituales en contextos del Paleolítico medio, y esa disyuntiva tecnológica no altera el resultado de la interpretación del conjunto lítico que tratamos en este trabajo.

En cuanto al SSDA, se trata de cantos globulares que se explotan produciendo lascados que generan relaciones angulares cercanas a los $90^{\circ}$, a medida que se va rotando el núcleo. La existencia de planos secantes, en los que se intercambian los roles de superficie de extracción y plano de percusión de forma continua, favorece un tipo de extracción en el que puede haber talones lisos, e incluso alguno diedro, con ángulos cercanos a los $90^{\circ}$. Este tipo de talones, que han sido identificados en el conjunto, podrían asociarse con este método que hemos identificado a partir de 3 núcleos. Por otra parte, la explotación Levallois generaría unas relaciones angulares similares e incluso algo mayores, entre los $90^{\circ}$ y los $100^{\circ}$, siendo además frecuentes los talones de tipo facetado o diedro.

Por su parte, los NUPC se caracterizan por series de talla limitadas y que no agotan el núcleo, ni alternan plataformas de talla y percusión, resultando un canto que podría confundirse con un canto trabajado. La presencia en el conjunto de lascas corticales o con restos de córtex, podría relacionarlas con este método de talla o con el uso de los cantos (percutores, cantos trabajados). Como consecuencia de este tipo de explotación, los productos de talla tienden a presentar talones corticales, lo cual se documenta en 31 de las lascas analizadas en Bañugues.

Podemos resumir que en Bañugues las matrices utilizadas como núcleos son en su mayoría cantos rodados, así como en menor medida alguna lasca (mayor abundancia de soportes de tamaño medio y pequeño) las cuales utilizan la parte ventral como superficie de lascado. Los métodos de talla empleados en Bañugues son variados, estando fuertemente condicionados por las matrices utilizadas, los cantos rodados de cuarcita, adaptando el método de explotación al tipo de soporte. También hay que resaltar que parece una estrategia bastante habitual el intercambio de métodos o la adaptación a un método u otro en función de la evolución morfológica del núcleo, a medida que éste se va reduciendo y van variando sus relaciones angulares entre planos de percusión y superficies de extracción. Por esta razón, algunos núcleos Levallois podrían terminar siendo discoides, al igual que los NUPC podrían convertirse en SSDA.

De igual modo, se ha observado la utilización como plano de percusión de superficies corticales y lisas indistintamente. En este caso, la preparación del plano de golpeo, y como consecuencia el facetado, es una estrategia secundaria dentro del proceso de explotación, provocado por la ausencia de ángulos propicios para el golpeo en determinados soportes. Por esta razón, no parece ser un planteamiento predefinido y estandarizado en el yacimiento, para la obtención de lascas, tratándose más bien de una solución técnica para la obtención de productos concretos.

En este sentido podemos comparar esta circunstancia con otros casos documentados para el Paleolítico medio al aire libre de la Región Cantábrica, como sucede en el yacimiento de El Habario, donde se ha realizado la siguiente observación: "Las superficies de golpeo se encuentran en ocasiones acondicionadas, combinándose en un mismo núcleo con la superficie cortical para el golpeo. Tal circunstancia delata que el acondicionamiento del punto de impacto y el correspondiente facetaje del producto final son muchas veces respuestas coyunturales" (CARRIÓN y BAENA, 2005).

En definitiva, y como se ha indicado para el Paleolítico medio de otras zonas del cantábrico oriental y de la región pirenaica, o incluso en otras zonas del interior peninsular (CASANOVA et al., 2008; RÍOS, 2008; ÁLVAREZ ALONSO y FERNÁNDEZ FERNÁNDEZ, 2012), parece ser una constante la variabilidad y versatilidad de los métodos de talla empleados en contextos musterienses, que sin duda se adaptan perfectamente a los tipos, morfologías y calidades de las materias primas disponibles.

\subsection{Elementos retocados}

En cuanto a los elementos retocados, hay un total de 37 (Fig. 13) incluyendo 2 núcleos con retoque, lo que supone el $9,76 \%$ del total del conjunto dividido en: 10 escotaduras, 9 raederas, 9 denticulados, 3 lascas retocadas, 1 raspador, 1 buril, 1 perforador y 1 punta Levallois. Se trata de un conjunto limitado y poco representativo como corresponde igualmente a una colección escasa, a pesar de lo cual es de destacar que los elementos retocados sobre lasca constituyen el grupo más importante, ya que el macro-utillaje apenas es significativo en el total del yacimiento. Es una característica de este conjunto lítico la poca incidencia de los útiles configurados en detrimento de las Cadenas Operativas de debitado y su empleo para la fabricación de soportes retocados (raederas y denticulados), una pauta que se repite en otros conjuntos similares como Lezetxiki, La Verde o El Barandiallu (ÁLVAREZ ALONSO, 2010a; 2013; ÁLVAREZ ALONSO y ARRIZABALAGA, 2012). Casi todas las piezas han sido retocadas mediante retoque simple o denticulado, destacando dos con retoque sobreelevado.

${ }^{6}$ en este caso la diferenciación entre el método quina y el SSDA, no es muy nítida en Bañugues. 

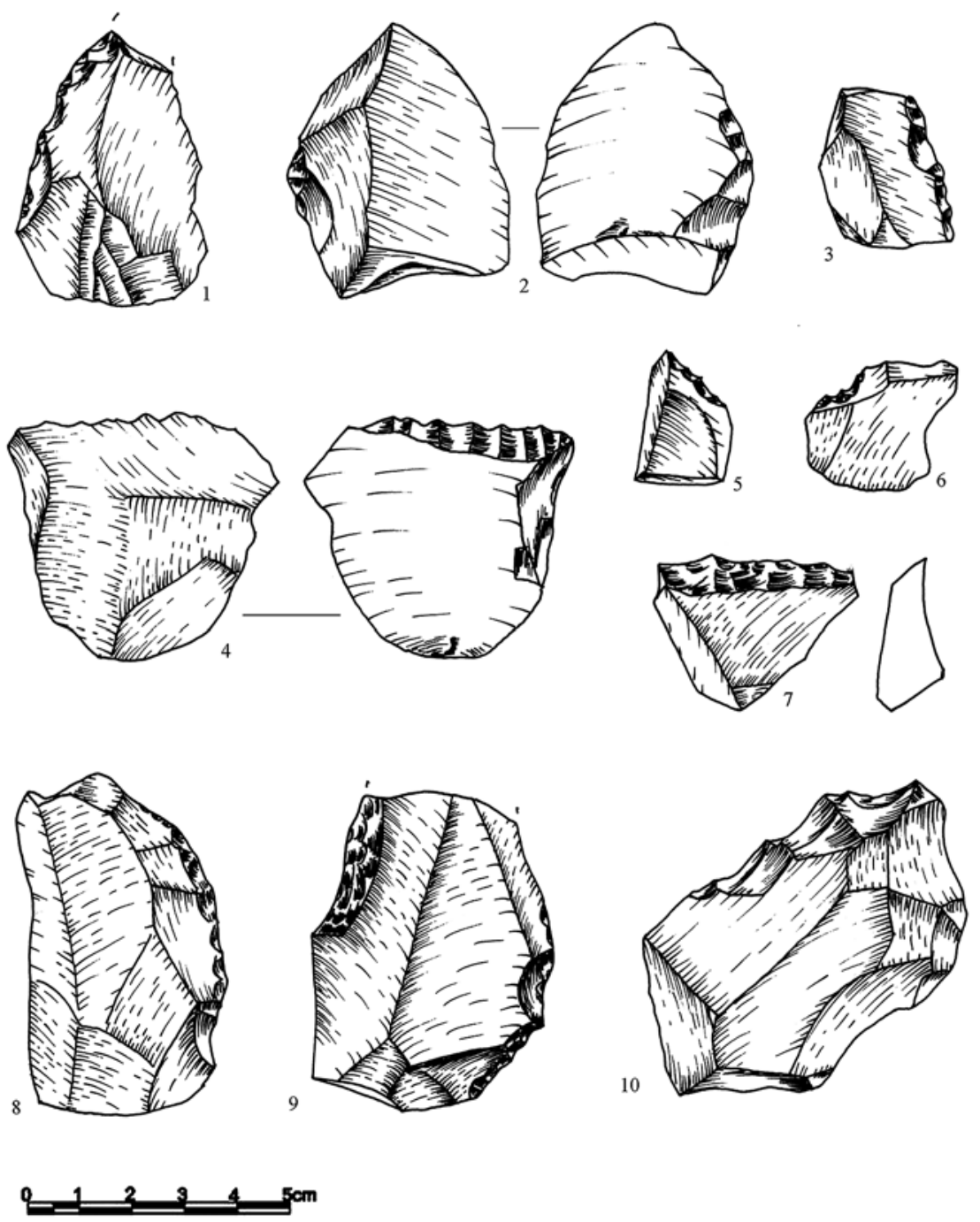

Fig. 13. Utillaje. Piezas retocadas. / Tools. Retouched pieces

\subsection{Las colecciones líticas de superficie de Bañugues}

De Bañugues existen varias colecciones líticas, procedentes de recogidas de superficie, en las que se mezclan los materiales de los dos horizontes arqueológicos presentes en la ensenada, y compuestas principalmente por material significativo, principalmente macro-utillaje.

Obviamente, todos los materiales recuperados en superficie son fruto de una selección que se basa en criterios como "lo más llamativo", "lo más representativo" o simplemente "lo que se ha identificado o visto". Estas recogidas no pueden ser representativas, en ningún caso, del tipo de industria presente en el yacimiento de Bañugues, sobre todo, cuando somos conscientes de que en estas recogidas se han mezclado materiales del horizonte asturiense y del Paleolítico medio que son difícilmente distinguibles, como ocurre con muchos de los núcleos, restos de talla, lascas simples o cantos tallados. Estos elementos de la Cadena Operativa son fundamentales para proceder al análisis del conjunto, pero sobre todo para obtener una vi- sión, ya no sólo tipológica, sino también tecnológica, que se revela fundamental en este tipo de contextos como el que mostramos en este trabajo.

El valor que debemos dar a los conjuntos de superficie, debe ser el de una visión global del tipo de elementos representados. En este caso, podemos deducir la importancia de los cantos tallados dentro del conjunto de Bañugues, algo que se ha constatado en la excavación y que, como hemos visto, no sólo responde a la presencia de utillaje clasificado como "cantos trabajados" sino también a actividades de talla (percutores) y a métodos de reducción orientados a la obtención de lascas (núcleos sobre canto). Por otra parte, la escasa representación de elementos de macro-utillaje (bifaces y hendedores) en la excavación resulta muy significativa, por lo que las piezas documentadas en superficie nos ayudan a entender que sí existieron en el yacimiento, tal vez no como un elemento principal, pero sí importante. La pervivencia de este tipo de elementos en contextos musterienses avanzados es algo que a día de hoy es incuestionable, como sucede en 
el norte de la Península Ibérica con los pequeños bifaces y hendedores presentes en El Barandiallu (ÁLVAREZ ALONSO, 2010a, 2013), Abri Olha 2 (LAPLACE y SÁENZ DE BURUAGA, 2000), Amalda (BALDEÓN, 1990), Abauntz (MAZO et al., 2011-2012) o Isturitz (DELPORTE, 1974); en los niveles musterienses con hendedores de La Viña (FORTEA, 1999), El Castillo (CABRERA, 1984), Cueva Morín (GONZÁLEZ ECHEGARAY y FREEMAN, 1978) o Gatzarria (LAPLACE y SÁENZ DE BURUAGA, 2003); o más recientemente en la cueva de El Sidrón -donde se recuperó una pieza de macro-utillaje bifacial en un contexto musteriense- (SANTAMARÍA et al.2011), y en los niveles inferiores de la cueva de Arlanpe, situados en el límite del Pleistoceno medio y superior, asignados al Paleolítico medio antiguo, donde también hay presencia de macroutillaje bifacial (RÍOS et al. 2011).

Casi todo lo que ha trascendido en la bibliografía sobre Bañugues, ha estado muy condicionado por los conjuntos líticos de superficie, como así sucede con el estudio de R. Montes (2003) que revisa diversos materiales, un total de 422 procedentes de recogidas y excavación (sólo la campaña de 1977) y por lo tanto mezclando los resultados de la serie estratigráfica ( $n=130$ piezas) con parte de la serie de superficie ( $n=292$ piezas). La imagen otorgada por estas colecciones, con abundancia de cantos tallados y en menor medida de elementos de macroutillaje (bifaces y hendedores), ha prevalecido sobre otras consideraciones de aspecto tecnológico en las que sí podemos ahondar procediendo fundamentalmente a un análisis del material hallado en contexto estratigráfico que, a día de hoy, representa la colección más fiable para interpretar el yacimiento de Bañugues. Nuestra visión actual, centrada en el material contextualizado, viene a corregir y matizar interpretaciones anteriores donde se incorporaba fundamentalmente el material descontextualizado. De este modo, creemos poder precisar aún más cualquier consideración crono-cultural con el estudio aquí expuesto, ya que realizar un análisis conjugando la generalidad sesgada de estos conjuntos de superficie, sería poco ajustado a la realidad.

\subsection{Síntesis de la industria lítica}

El conjunto lítico de Bañugues está caracterizado por la presencia en el entorno inmediato al yacimiento de abundante materia prima en formato de cantos rodados de cuarcita, a partir de los cuales se siguen unas estrategias de talla que se adaptan a la variedad de morfologías presentes en los cantos, intercambiando roles e incluso variando el método de explotación en el transcurso de la propia reducción del núcleo. Por lo tanto, queda patente la gran versatilidad de los conocimientos técnicos del grupo humano artífice de este conjunto industrial. Por otra parte, se observa otra Cadena Operativa, de menor incidencia, encaminada a la obtención de soportes de mayor tamaño (tanto de lascas como de elementos masivos, que posteriormente son configurados o retocados). Aunque en este último caso sólo encontramos productos finales.
Ninguna de las Cadenas Operativas está completa; mientras que los elementos configurados parece que no han sido elaborados en el yacimiento (al menos en la zona excavada), el resto de procesos de talla y elaboración de útiles sí parecen haber sido realizados en el mismo lugar, pero no en sus fases iniciales (captación, testado, desbastado, etc...). Los núcleos y cantos han sido aportados previamente seleccionados $y$, en ocasiones parcialmente desbastados, a juzgar por el bajo grado de corticalidad del conjunto y las conclusiones que hemos expresado sobre esta circunstancia. Las estrategias de captación, talla y fabricación de utillaje indican un cierto grado de complejidad espacial y tecnológica, del mismo modo que todos los rasgos tecno-tipológicos anteriormente analizados nos indican la pertenencia de este conjunto industrial al Paleolítico medio. La existencia de macro-utillaje en el yacimiento, pero también en las numerosas y abundantes colecciones recogidas en superficie, no desentona en absoluto con los conjuntos propios del Paleolítico medio con presencia de macro-utillaje, como es el caso más cercano de El Barandiallu (ÁLVAREZ ALONSO, 2010a, 2013) o los niveles inferiores de El Castillo (CABRERA, 1984). Estos conjuntos vienen siendo identificados a lo largo de la Región Cantábrica, desde las fases finales del Pleistoceno medio (ÁLVAREZ ALONSO, 2010a, 2011, 2012, 2014) distanciándose e individualizándose netamente de los conjuntos achelenses.

\section{4.- BAÑUGUES EN EL CONTEXTO PENINSULAR}

En un principio, y ante la falta de información cronológica, se pensaba en una perduración del Achelense en la Región Cantábrica hasta al menos el OIS 5 (RODRÍGUEZ ASENSIO, 1983, 2000). Las investigaciones llevadas a cabo en los últimos quince años no permiten confirmar que esto haya sido verdaderamente así, a tenor de las escasas evidencias geoarqueológicas para sustentar esta situación y si además tenemos en cuenta el contexto general para la Península Ibérica que se indica a continuación.

En la Península Ibérica, desde finales del Pleistoceno medio, las industrias achelenses parecen coexistir con las primeras evidencias de un Paleolítico medio que ya estaría presente, al menos desde el OIS 9 (llegando en algún caso a retrotraerse hasta el OS 11) en yacimientos como Ambrona, Bolomor, Atapuerca TD 11 / TD 10 o Cuesta de la Bajada (FERNÁNDEZ PERIS et al., 2008; FALGUÈRES et al., 2001, SANTONJA y PÉREZ GONZÁLEZ, 2006). El tecno-complejo achelense, por su parte, parece perdurar hasta el OIS 7 (SANTONJA y PÉREZ GONZÁLEZ, 2010a), por lo que el final del Pleistoceno medio y el inicio del superior parece ser un momento caracterizado por industrias asignadas a un Paleolítico medio antiguo (con macro-utillaje bifacial), en el que no está descartado la existencia de dos tecno-complejos líticos diferentes que llegan a converger en distintos puntos de la Península: el final de Achelense y las primeras manifestaciones de un temprano Paleolítico medio.

En lo que respecta a la presencia de industrias del Paleolítico medio en contextos avanzados del Pleistoceno 
medio, o en los inicios del Pleistoceno superior, existen varios ejemplos en la Región Cantábrica, donde contamos con una serie de dataciones y conjuntos industriales asignados al OIS 5 (ÁLVAREZ ALONSO, 2010a; 2012; 2014) que muestran un panorama parecido al que presenta el resto de la Península para esas cronologías. Las pocas dataciones existentes provienen en su totalidad del centro y oriente de la región (Cantabria, Vizcaya y Guipúzcoa).

De este modo, tenemos dos dataciones de $92.800 \mathrm{BP}$ y $89.000+11 /-10$ BP, para el nivel 23 de El Castillo, en la base de la secuencia musteriense que, junto a la cueva de Covalejos, con una datación por U/Th de 101 ka BP, sitúan el inicio de las clásicas series líticas musterienses cantábricas en un momento avanzado del OIS 5 (BISCHOFF et al., 1992; CABRERA y BERNALDO DE QUIRÓS, 2000; MARTíN et al., 2006). La secuencia inferior de La Garma A exterior ha sido encuadrada aproximadamente entre el OIS 6 y el OIS 5e, a partir de la datación por racemización de aminoácidos, que permiten situar el final de esta secuencia basal en un momento anterior al inicio del Pleistoceno superior (TAPIA, 2010).

En la cueva de Arlanpe (Vizcaya) los niveles C y D (RíOS et al., 2011), entre los que se documenta la técnica Levallois, utillaje sobre lasca y algunos elementos espesos de macro-utillaje bifacial, poseen una aproximación cronológica en torno al OIS 5e, encajando bastante bien en el esquema planteado para el resto de la Región Cantábrica.

En la cueva de Lezetxiki, los niveles basales (VII y VI) de la secuencia antigua han sido encuadrados en el Paleolítico medio antiguo, a partir de la interpretación de las distintas dataciones existentes y del análisis del resto de componentes (industria lítica, sedimentología, fauna, registro paleoambiental), a una horquilla que los situaría entre el OIS 6 y 5e aproximadamente (ÁLVAREZ ALONSO y ARRIZABALAGA, 2012; FALGUÈRES et al., 2006).

También nos resultan interesantes las recientes investigaciones efectuadas en Cueva Corazón (Palencia), en la vertiente sur de la Cordillera Cantábrica, en el corredor que une esta región con la cuenca del Duero (cañón de la Horadada). En este yacimiento se ha documentado una importante ocupación atribuida al Musteriense antiguo, en la que se han obtenido dos dataciones por TL para su nivel 2 a partir de cuarcitas termo-alteradas, de 96.567 \pm 7806 BP y 95.763 \pm 7456 BP (SÁNCHEZ YUSTOS et al., 2011). Por otra parte, en el extremo más occidental del Cantábrico, ya en la cuenca del Miño, se localiza Cova Eirós, cuyo nivel 3 musteriense, ha sido datado por OSL en 84.807 4919 años BP (LAZUÉN et al., 2011).

En el resto de regiones de la Península Ibérica, también abundan los contextos de similares características, como así sucede en el valle del Duero, donde recientemente ha sido estudiado un yacimiento de finales del Pleistoceno medio que encaja en el Paleolítico medio antiguo (situado en la transición del Paleolítico inferior al medio). Se trata de Valdecampaña 4, en donde se ha obtenido una datación por TL de $143.464 \pm 10872$ BP, correspondiente con el OIS 6 (DÍEZ MARTíN et al., 2008).
Más hacia el sur, ya en el Sistema Central, y más concretamente en el valle alto del río Lozoya (Sierra de Guadarrama), se localizan los yacimientos de Pinilla del Valle, con una edad que sitúa el poblamiento musteriense en esta zona del interior peninsular en los inicios del Pleistoceno superior, con una fecha de $90.961 \pm 7.881 \mathrm{BP}$ por TL obtenida en el nivel 5 del yacimiento de "Cueva del Camino", encuadrado en el OIS 5 (MÁRQUEZ et al., 2008; ARSUAGA et al., 2012).

En la vertiente sur del Sistema Central, ya en el valle del Manzanares, se localiza el yacimiento de Estragales en la terraza compleja de Butarque, que ha aportado dos dataciones para un conjunto lítico coherente con un Paleolítico medio con macro-utillaje, de 107 +39/-22 BP obtenida por TL y 122.1 \pm 11.1 ka BP obtenida por OSL (PÉREZ GONZÁLEZ et al., 2008).

Por otra parte, en el Pre-Pirineo ilerdense, el yacimiento musteriense de Tragó ha arrojado una cronología aproximada de 126 ka para su nivel basal (UA3) (TORRE et al., 2013), mientras que en el Levante Peninsular, nos encontramos con la cueva del Bolomor, que posee una amplia secuencia musteriense con 17 niveles situados entre los OIS 5 y 9, datados por TL. Este yacimiento presenta a muro una cronología cercana a los 300 ka BP, fecha en este último caso obtenida por Th/U (FERNÁNDEZ PERIS, 2007; FERNÁNDEZ PERIS et al., 2008).

En el sur peninsular, también se localizan contextos que nos presentan un panorama coherente con el Paleolítico medio (en algún caso con macro-utillaje bifacial) para los inicios del OIS 5; son el nivel IX de la cueva del Angel $(121 \pm 10 \mathrm{ka}$ BP) (BOTELLA et al., 2006), la base de la estratigrafía de La Carigüela, situada entre 146 y 117 ka (VEGA et al., 1997) o incluso El Aculadero, datado por OSL en $110.507 \pm 7.481 \mathrm{BP}$ (SANTONJA y PÉREZ, 2010b).

De lo expuesto tanto en este punto como en el anterior, podemos extraer dos conclusiones fundamentales: en primer lugar el macro-utillaje bifacial (hendedores y bifaces) está presente en la Región Cantábrica y en el resto de la Península en contextos plenamente musterienses; en segundo lugar, las industrias del Paleolítico medio vienen documentándose en la Península Ibérica desde momentos muy tempranos, y parecen estar generalizadas al menos desde el OIS 6/5, siendo a partir de ese instante el único tecno-complejo reconocible en la Península Ibérica hasta avanzado el OIS 3.

\section{5.- DISCUSIÓN: EL DEBATE SOBRE EL PALEO- LIITICO MEDIO ANTIGUO CANTÁBRICO}

A la hora de interpretar el conjunto lítico de Bañugues es necesario traer a colación definiciones tales como "Vasconiense", "Musteriense de Tradición Achelense" y "Achelense meridional" (BORDES, 1953, 1961, 1971; CABRERA, 1983, 1989; DESCHAMPS, 2009-2010; SORESSI, 2002; TURQ et al., 2010), entre otras razones por cuestiones de carácter historiográfico. Estas definiciones, aunque hoy en día no deben ser entendidas dentro de la concepción gra- 
dualista en la que fueron acuñados, sí son expresiones que responden a realidades tecno-tipológicas muy particulares que se encuentran en los momentos finales del Pleistoceno medio y en el primer tramo del superior. Por tanto, sí debemos tomarnos la molestia de incluirlas cuando hacemos referencia a este interesante debate, como manifestaciones de una problemática que sí es real y que acompaña al proceso por el cual las industrias achelenses en el occidente europeo evolucionan, hasta dar lugar al Musteriense clásico.

Un caso similar al que nos encontramos en la Región Cantábrica, donde las industrias con bifaces parecen ser abundantes en el tránsito del Pleistoceno medio al superior, fue también documentado en su día en el territorio delimitado por los Pirineos y Aquitania. En esta zona se localizan varios yacimientos en contextos kársticos, pero sobre todo al aire libre -en terrazas fluviales y en zonas litorales-, donde la cuarcita es la materia prima predominante. Estos conjuntos tienen una composición tecno-tipológica con moderada representación de bifaces, abundancia de útiles sobre lasca, presencia de hendedores y técnicas variadas de reducción lítica (discoide, Levallois, kombewa o quina) que empiezan a mostrar un panorama diferente del Achelense clásico, ya a partir del OIS 8/7. A este panorama F. Bordes (1971) se refirió como "Achelense meridional", para hablar de unas industrias anteriores al Würm I y que se escapaban de la clásica secuencia de las terrazas del Somme. En la actualidad, esta visión de "facies" regionales no puede seguir siendo mantenida -al igual que la división tripartita del Achelense (SANTONJA, 1991-1992)- debiendo buscar una explicación a estas diferencias en cuestiones tales como la diferente conservación de los yacimientos, las distintas materias primas utilizadas, la propia dinámica evolutiva de los conjuntos de finales del Pleistoceno medio, o incluso la existencia de comportamientos tecno-económicos ligados a la movilidad de grupos humanos específicos.

En primer lugar, hoy en día este "Achelense meridional" ha sido mejor definido como Paleolítico medio antiguo (TURQ et al., 2010) y a nuestro modo de ver este caso sería extrapolable al Cantábrico, donde fue definido un "Achelense superior cantábrico" (RODRÍGUEZ ASENSIO, 1983, 2000; RODRÍGUEZ ASENSIO y ARRIZABALAGA, 2004), sobre el que hoy en día podemos hacer más precisiones (ÁLVAREZ ALONSO, 2010a; 2011; 2012; 2014; ARRIZABALAGA y RÍOS, 2012). La caracterización tecnotipológica de todos estos yacimientos franceses, unida a que suelen ser conjuntos líticos con escasos efectivos y en contextos al aire libre, nos recuerda al panorama cantábrico. Además, en este último contexto, al igual que relatan A. Turq et alii (2010), este "Achelense meridional" se define por yacimientos tradicionalmente atribuidos al Achelense -situados por encima del OIS 5, y abarcando los OIS 6 y 7 - que ya no deben seguir siendo considerados como pertenecientes a este tecno-complejo (TURQ et al., 2010). Actualmente, abandonamos las definiciones de Achelense merional o Achelense superior cantábrico para referirnos a esta problemática, con el objetivo de arrojar luz sobre el inicio de los cambios que desembocarán en el Musteriense clásico, el cual se hace evidente en el Cantábrico a partir del OIS 4.

Por otra parte, el Musteriense de Tradición Achelense (ver SORESSI, 2002) posee una connotación cultural mucho más rígida, a la par que un encuadre cronológico en un momento más avanzado; y no es nuestro objetivo ahondar en la problemática que ha planeado sobre las "facies musterienses". En el ámbito cantábrico, este término ha sido empleado para referirse a algunos yacimientos al aire libre y niveles musteriense en cueva, como por ejemplo: Bañugues, Llagú, El Castillo o El Barandiallu (RODRÍGUEZ ASENSIO, 1983; CABRERA, 1984; ESTRADA y JORDÁ, 2004; ÁLVAREZ ALONSO, 2013), entre otros. Esto se debía a que en la región existían contextos arqueológicos cuya adscripción tecnotipológica resultaba imprecisa entre el Achelense y el Paleolítico medio, fundamentalmente por la presencia de macro-utillaje y caracteres tecnológicos propios del Musteriense, o también simplemente por la presencia de hendedores y bifaces en contextos musterienses. El predominio de utillaje retocado sobre lasca, la presencia del método Levallois y una representación moderada de macro-utillaje bifacial, fueron argumentos esgrimidos a la hora de valorar la pertenencia de algunos conjuntos cantábricos al MTA, aunque no encajaran exactamente en la definición tipológica de ninguna de sus variantes (MTA-A y MTA-B). El MTA posee una connotación culturalista y cronológica demasiado rígida, adaptado a una casuística muy concreta de determinados yacimientos del occidente de Francia, que evidentemente no se reproduce miméticamente en el Cantábrico; aunque ello no quiera decir que no podamos plantear vínculos entre el MTA del suroeste francés y determinados niveles musterienses con macro-utillaje de la Región Cantábrica.

En definitiva, la existencia de un Achelense meriodional anterior al Eemiense, y un MTA posterior a este momento en Aquitania, sirvieron de referente para analizar los conjuntos con bifaces y hendedores, y los contextos musterienses antiguos que muchas veces, de manera imprecisa, se iban documentando a lo largo de la Región Cantábrica. El uso de esta terminología en el contexto del debate que nos ocupa, respondía a una composición tecno-tipológica de los conjuntos líticos que hoy en día encuentra mejor definición dentro del contexto del Paleolítico medio antiguo o Paleolítico medio con macro-utillaje, que nos encontramos a lo largo del Cantábrico. Uno de los mayores problemas que se nos han presentado tradicionalmente es el enorme lastre que conllevan muchas de las definiciones culturales (y tipológicas) con sus respectivas connotaciones historiográficas que se van reafirmando con el tiempo o van siendo rechazadas, con lo que ello implica a la hora de que los yacimientos sean valorados o considerados de una u otra manera.

Parece claro que el MTA, según los criterios por los que fue definido (BORDES, 1953, 1961; SORESSI, 2002) no está presente en el Cantábrico, ya que se trata de un constructo tipológico creado a partir de unas condiciones muy específicas (fundamentalmente derivadas de la cali- 
dad, abundancia, formatos y tamaños de las materias primas). Entonces ¿Cómo podemos abordar todo lo relativo a los inicios del Paleolítico medio cantábrico y los conjuntos musterienses con macro-utillaje, sin prestar atención a las ocupaciones neandertales de las regiones vecinas? No parece haber duda de la conexión y los vínculos existentes entre el Musteriense del ámbito aquitano-pirenaico y la Región Cantábrica. Se entienden pues, como fenómenos próximos adaptados a las condiciones de subsistencia (materias primas, movilidad, habitabilidad, etc...) de cada región. De este modo, lo que nos debe importar, por encima de la estructura tipológica de cada conjunto (o del nombre que lo defina), es la pervivencia de determinados esquemas operativos en los que hay una continuidad a lo largo del Paleolítico medio en esta amplia área, con la presencia de determinado macro-utillaje, y asociados tanto a contextos al aire libre como en cueva.

Por otra parte, el Vasconiense, es otra de las "facies musterienses", mucho más controvertida que el MTA, que han sido constantemente traídas a este mismo debate. Definido por F. Bordes (1953), fue rápidamente puesto en cuestión por las críticas generadas por el modelo de facies (BINFORD y BINFORD, 1966) y discutido en la investigación cantábrica, especialmente por L.G. Freeman (1966) y V. Cabrera (1983, 1984), que negaban la posibilidad de individualizarlo solo en base a la presencia de hendedores en algunos niveles musterienses ${ }^{7}$. Recientemente, el Vasconiense ha vuelto al debate tras recientes estudios en los que se plantean las estrechas relaciones tecnológicas que se pueden establecer entre los niveles musteriense con presencia de hendedores del Cantábrico y del occidente pirenaico, (DESCHAMPS, 2009-2010; MAZO et al., 2011-2012). Dejando la cuestión de las facies musterienses al margen, la abundancia de un macro-utillaje muy específico (hendedores y bifaces) de oriente a occidente a lo largo de la Región Cantábrica, y tanto en cueva como al aire libre, muestran la influencia, la importancia y la pervivencia de este tipo de útiles, y tal vez nos pudiera permitir ponerlo en relación con lo que sucede en Aquitania, por qué no como como una variante del MTA. Seguramente, como se ha resaltado recientemente (MAZO et al., 20112012) estudios más exhaustivos sobre esta cuestión permitirían arrojar más luz sobre este Musteriense con macro-utillaje que, a día de hoy y al margen de su denominación (MTA, Vasconiense, etc...), demuestra la gran homogeneidad que presentan diversos yacimientos del norte peninsular entre sí. No podemos obviar que en la Región Cantábrica existen varios niveles asociados al Musteriense, que se caracterizan por la presencia de un tipo de hendedores muy similares, así como por una variedad y número de bifaces limitado.

Los conjuntos líticos y los diversos niveles de finales del Pleistoceno medio e inicios del superior en el Cantábrico, se han ido definiendo según sus características más notables, obviando que las industrias líticas no son siste- mas rígidos y cerrados que definen de manera exclusiva un periodo cronológico o un tramo cultural determinado. Los conjuntos líticos que componen el Paleolítico antiguo cantábrico son bastante más dinámicos de lo que pudiera pensarse, ya que podemos afirmar que la variabilidad tecno-tipológica que presentará el Musteriense clásico en la región (CARRIÓN et al., 2008) no supone una novedad que se produce con la llegada del Pleistoceno superior. Los grupos humanos que habitaron la Región Cantábrica a finales del Pleistoceno medio confeccionaron su utillaje en función de las necesidades específicas que se les planteaban, además del bagaje cultural implícito en todo proceso antrópico, con lo cual las industrias líticas resultantes son variadas, responden seguramente a funcionalidades diversas y sobre todo están adaptadas a las materias primas presentes en cada sector de la región. A pesar de ello, se trasluce una relativa homogeneidad en muchos de los conjuntos que, a modo de propuesta, hemos englobado en lo que denominamos Paleolítico medio antiguo cantábrico (ÁLVAREZ ALONSO, 2010a; 2011; 2012; 2014), aunque es probable que muchos de ellos no sean precisamente "antiguos". Entre estos conjuntos y sin ser todos iguales, hay más cosas que les aproximan que características que les alejen, encuadrándose además todos ellos en un mismo horizonte crono-estratigráfico que situamos durante el OIS 5 -y probablemente también desde el OIS 7-6-. Cuestión aparte es plantear si este Paleolítico medio antiguo perdura hasta un momento avanzado del Musteriense, conservando algunas de sus características específicas, y dando lugar a plantear una conexión más estrecha con el MTA francés, que lejos de desecharse, resulta cada vez más evidente.

\section{6.- CONCLUSIONES}

En este trabajo hemos presentado los resultados del análisis de una parte inédita del conjunto lítico de Bañugues, realizando un estudio no sólo desde un punto de vista tecno-tipológico, sino también tratando de realizar una reflexión historiográfica sobre la caracterización de los yacimientos cantábricos del final del Pleistoceno medio e inicios del superior. Bañugues es un yacimiento clásico, que en los últimos treinta años ha servido de modelo para muchas de las interpretaciones que se han barajado para conjuntos de similares características a lo largo de la región. Con este trabajo queremos sumarnos al debate sobre el Paleolítico antiguo regional, en el que se está debatiendo la recalificación de algunos conjuntos, dentro de lo que hoy en día encuentra mejor definición dentro del Paleolítico medio.

En primer lugar su conjunto lítico, que a día de hoy nos parece que encaja perfectamente dentro de las definiciones y contextos que se han descrito a lo largo de la Península Ibérica y el suroeste francés para el Paleolítico medio antiguo (o al menos un Paleolítico medio con macroutillaje). En segundo lugar, desde un punto de vista geo-

\footnotetext{
${ }^{7}$ Además de considerar que estos hendedores aparecían en contextos demasiado heterogéneos como para poder ser adscritos a una facies en concreto.
} 
morfológico, debemos olvidar cualquier asociación del depósito sedimentario inferior de Bañugues con una terraza de edad eemiense, que otorgaría una datación relativa dentro del OIS 5e, ya que queda demostrado, como se barajó en más de una ocasión (RODRÍGUEZ ASENSIO y FLOR, 1983) que se trata de un depósito de ladera desplazado desde una cota superior hasta su posición actual ${ }^{8}$.

Por otra parte, también tratamos de acercarnos a un debate más historiográfico, en el que la terminología ha jugado un papel casi o más trascendente que la propia caracterización tecno-tipológica. Términos como Musteriense de Tradición Achelense, Vasconiense, Achelense meridional o Achelense superior cantábrico, hacen referencia a una serie de conjuntos que, grosso modo, hemos encuadrado en la Región Cantábrica bajo la etiqueta de Paleolítico antiguo cantábrico (RODRÍGUEZ ASENSIO, 2000; RODRÍGUEZ ASENSIO y ARRIZABALAGA, 2004; ÁLVAREZ ALONSO, 2010a; 2011; 2012). Estas denominaciones usadas clásicamente para conjuntos musterienses con presencia de hendedores (El Castillo 200 Morín 22), bifaces (niveles 24 y 25 de El Castillo), o para contextos al aire libre con presencia de macro-utillaje, útiles sobre lasca y elementos Levallois de difícil ubicación entre el Paleolítico inferior o medio, son las que muestran la continuidad entre las industrias achelenses y musterienses en la Cornisa Cantábrica. Una continuidad que, tamizada por las especiales condiciones de conservación, las series líticas limitadas, la ausencia de dataciones y los distintos medios geológicos que se han documentado (cuevas, terrazas fluviales, medios edáficos, contextos litorales) ha intentado ser definida a lo largo de la investigación a partir de una excesiva parcelación de los distintos y escasos yacimientos.

En cualquier caso, no podemos descuidarnos de que los nombres y las definiciones, muchas veces hacen referencia a cajones (más o menos estancos) en los que se pretende colocar a los conjuntos líticos, unas veces de forma más forzada que otras. Estos cajones, falsamente estancos, se han elaborado bajo criterios tipológicos, pero también bajo criterios tecnológicos (suplantan muchas veces a la rigidez tipológica por una rigidez tecnológica), y que en cualquier caso responden a divisiones condicionadas por criterios que no tienen por qué ser siempre coincidentes y que se van encadenando en el tiempo.

Sin olvidar ni obviar las connotaciones del debate y de todas las periodizaciones preexistentes, debemos tratar de simplificar la cuestión, ya que el escaso número de yacimientos presentes en el Cantábrico con cronologías contemporáneas o anteriores al OIS 5 así nos lo impone. Los fundamentos de esta estructuración del problema, en la que consideramos que en un momento avanzado del Paleolítico antiguo cantábrico existe un 'Paleolítico medio antiguo' se exponen ampliamente en algunos trabajos previos (RODRÍGUEZ ASENSIO y ARRIZABALAGA, 2004; ÁLVAREZ ALONSO, 2010a; 2011; 2012, 2014).

El yacimiento de Bañugues parece situarse en mitad de esa dinámica de cambio experimentada por los grupos humanos de finales del Pleistoceno medio, que se hace patente en progresivos cambios y modificaciones de los tecno-complejos líticos. Estos cambios están avanzando las características de un Musteriense que en el Cantábrico estará ampliamente implantado, evidenciando que no se trata de una novedad acontecida en el Pleistoceno superior, sino de un proceso que empieza a atisbarse al menos, y con los datos que tenemos a fecha de hoy, durante el OIS 6.

\section{BIBLIOGRAFÍA}

\section{ÁLVAREZ-ALONSO, D}

2004 Individualización de los métodos de reducción lítica en el Paleolítico antiguo de Bañugues (Gozón, Asturias). Homenaje a Victoria Cabrera Valdés. Espacio, Tiempo y Forma I, 16-17: 49-62.

2010a Las primeras ocupaciones cantábricas. La evolución del hábitat humano en el medio cantábrico durante el Paleolítico antiguo. Tesis Doctoral. Departamento de Prehistoria y Arqueología. UNED. 668 p.

2010b La investigación de las primeras ocupaciones humanas en la Región Cantábrica. Espacio, Tiempo y Forma I, Nueva época. Prehistoria y Arqueología, 3: 9-20.

2011 El Paleolítico antiguo en la Región Cantábrica: un estado de la cuestión. Férvedes, 7: 29-37.

2012 El primer poblamiento humano en la región cantábrica. Reflexiones y síntesis en torno al Paleolítico antiguo. Kobie, 31: 21-44

2013 El Paleolítico en la cuenca del río Aboño (Llanera). Excavaciones en los yacimientos de El Barandiallu y la cueva del Olivo. Excavaciones Arqueológicas en Asturias 2007-2012. Consejería de Cultura, Principado de Asturias: $57-68$.

2014 First Neanderthal settlements in northern Iberia: The Acheulean and the emergence of Mousterian technology in the Cantabrian region. Quaternary International, 326327: 288-306.

\section{ÁLVAREZ-ALONSO, D. y ARRIZABALAGA, A.}

2012 La secuencia estratigráfica inferior de la cueva de Lezetxiki (Arrasate, País Vasco). Una reflexión necesaria. Zephyrus, LXIX: 15-39.

\section{ÁLVAREZ-ALONSO, D. y FERNÁNDEZ FERNÁNDEZ, J.}

2012 El conjunto lítico musteriense de la raña de Cañamero (Cáceres, España). Análisis tecnotipológico y tafonómico. Munibe, 63: 27-43.

ARRIZABALAGA VALBUENA, A. y RÍOS GARAIZAR, J.

2012 The first human occupation of the Basque crossroads. Journal of World Prehistory, 25: 157-181.

${ }^{8}$ Los trabajos geoarqueológicos en curso que estamos efectuando en el yacimiento, así parecen constatarlo. En consecuencia, no se puede sostener hoy en día la adscripción del depósito de Bañugues al OIS 5. 
ARSUAGA, J. L., BAQUEDANO, E., PÉREZ GONZÁLEZ, A., SALA, N., QUAM, R.M., RODRÍGUEZ, L., GARCÍA, R., GARCÍA, N., ALVAREZ-LAO, D., LAPLANA, C., HUGUET, R., SEVILLA, P., MALDONADO, E., BLAIN, H.-A., RUIZ ZAPATA, B., SALA, P., GIL GARCÍA, Mª. J., UZQUIANO, P., PANTOJA, A. y MÁRQUEZ, B.

2012 Understanding the ancient hábitats of the last-interglacial (late MIS 5) Neanderthals of central Iberia: Paleoenvironmental and taphonomic evidence from the Cueva del Camino (Spain) site. Quaternary International, 275: 55-75.

\section{BALDEÓN, A.}

1990 La industria lítica de los niveles paleolíticos. En: ALTUNA, J. et al. (eds.). La cueva de Amalda (Zestoa, País Vasco). Ocupaciones paleoliticas y postpaleolíticas. San Sebastián: Eusko Ikaskuntza: 63-115.

\section{BINFORD, L.R. y BINFORD, S.}

1966 A preliminary analysis of functional variability in the Mousterian of Levallois facies. American Anthropologist, 68 (2) 238-295.

\section{BISCHOFF, J. L., GARCÍA, J. F. Y STRAUS, L. G.}

1992 Uranium-series Isochron Dating at El Castillo Cave (Cantabria, Spain): The Acheulean/Mousterian question. Journal of Archaeological Science vol.19 (1)

\section{BORDES, F.}

1953 Essai de Classification des industries moustériennes. Bulletin de la Societé Préhistorique Française, 50: 457-466.

1961 Typologie du Paléolithique ancien et moyen. Publications de I'Institut de Préhistoire de l'Université de Bordeaux, mém. n. ${ }^{\circ} 1,2$ vol.

1971 Observations sur l'Acheuléen des Grottes en Drodogne. Munibe, XXIII: 5-23.

BOTELLA, D., BARROSO, C., RIQUELME, J., ABDESSADOCK, S., VERDÚ, L., MONGE, G. y GARCÍA, J.

2006 La cueva del Ángel (Lucena, Córdoba), un yacimiento del Pleistoceno medio y superior del sur de la Península lbérica. Trabajos de Prehistoria, 63 (2): 153-165.

\section{CABRERA VALDÉS, V.}

1983 Notas sobre el Musteriense cantábrico: el "Vasconiense". Homenaje al prof. Martín Almagro Basch, Vol. 1: 131-141.

1984 La cueva de El Castillo (Puente Viesgo, Santander). Bibliotheca Praehistorica Hispana, vol. XXII. CSIC, Madrid.

1989 El Paleolítico medio cantábrico y sus relaciones con el área pirenaica. Espacio, Tiempo y Forma, S.I. Prehistoria y Arqueología, 2: 49-59.

\section{CABRERA VALDÉS, V. y BERNALDO DE QUIRÓS, F.}

2000 Excavaciones arqueológicas en la cueva de El Castillo (Puente Viesgo). Actuaciones Arqueológicas en Cantabria, 1984-1999. Consejería de Cultura y Deporte de Cantabria: 23-32.

CARRIÓN, E. y BAENA, J.

2005 El Habario. Una ocupación musteriense al aire libre en los Picos de Europa. en Neandertales Cantábricos. Museo y Centro de Investigación de Altamira, monografía n 20 : 443-460.
CARRIÓN SANTAFÉ, E., BAENA PREYSLER, J., CONDE RUIZ, C., CUARTERO MONTEAGUDO, F. y ROCA, M.

2008 Variabilidad tecnológica en el Musteriense de Cantabria. Treballs d'Arqueologia 14: 279-318.

CASANOVA, J., MORA, R., MARTÍNEZ-MORENO, J. y TORRE, I de la.

2008 Diversidad y continuidad de los sistemas técnicos del Paleolítico medio en los Pirineos sur-orientales. Treballs d'Arqueologia, 14: 27-63.

DELPORTE, $\mathrm{H}$.

1974 Le Moustérien d'Isturitz d'après la Collection Passemard (Musée des Antiquités Nationales). Zéphyrus, XXV: 17-42.

DESCHAMPS, M.

2009-10 Le Vasconien: révision de sa signification à partir des industries lithiques d'Olha I et II,d'Isturitz et de Gatzarria. Paléo, 21: 103-126.

DíEZ MARTíN, F., SÁNCHEZ, P., GÓMEZ GONZÁLEZ, J. A. Y GÓMEZ DE LA RÚA, D.

2008 La ocupación paleolítica en los páramos del Duero: nuevos datos procedentes de Valdecampaña (Olivares de Duero, Valladolid). Zephyrus, 62: 19-39.

ESTRADA, R. y JORDÁ PARDO, J. F.

2004 Arqueología y gas natural: el Paleolítico medio de El Barandiallu (Villabona, Llanera, Asturias central). XI Reunión nacional de Cuaternario, Oviedo 2, 3 y 4 de Julio 2003. Oviedo: 253-260

FALGUĖRES, Ch., BAHAIN, J. J., YOKOYAMA, Y. BISCHOFF, J. L., ARSUAGA, J.L., BERMÚDEZ DE CASTRO, J.M., CARBONELL, E.y DOLO, J. M

2001 Datation par RPE et U-Th des sites pléistocenes d'Atapuerca: Sima de los Huesos, Trinchera Dolina et Trinchera Galería. Bilan géochronologique. L'Anthropologie, 105: 71-81.

FALGUĖRES, Ch., YOKOYAMA, Y. Y ARRIZABALAGA, A.

2006 La geocronolgía del yacimiento pleistocénico de Lezetxiki (Arrasate, País Vasco). Crítica de las dataciones existentes y algunas nuevas aportaciones. Munibe 57, Homenaje a Jesús Altuna: 93-106.

FERNÁNDEZ PERIS, J.

2007 La Cova del Bolomor (Tavernes de la Valldigna, Valencia). Las industrias líticas del Pleistoceno medio en el ámbito del Mediterráneo peninsular. Servicio de Investigación Prehistórica, Diputación Provincial de Valencia. Serie de Trabajos Varios, $n^{\circ} 108$.

FERNÁNDEZ PERIS, J., BARCIELA, V., BLASCO, R., CUARTERO, F. y SAÑUDO, P.

2008 El Paleolítico medio en el territorio valenciano y la variabilidad tecno-económica de la Cova del Bolomor. Treballs d'Arqueologia, 14: 141-169.

FORTEA PÉREZ, J.

1999 Abrigo de La Viña. Informe y primera valoración de las campañas de 1995 a 1998. Excavaciones Arqueológicas en Asturias 1995-98: 31-41. 
FREEMAN, L. G.

1966 The nature of Mousterian facies in Cantabrian Spain. American Anthropologist, 68 (2): 230-237.

\section{GONZÁLEZ FERNÁNDEZ-VALLES, J. M}

1968 El Paleolítico Inferior y Medio en Asturias. Nuevos hallazgos. Archivum, XVIII: 1-36

GONZÁLEZ ECHEGARAY, J. y FREEMAN, L. G.

1978 Vida y muerte en Cueva Morín. Institución Cultural de Cantabria

\section{HOYOS GÓMEZ, M}

1976 El Cuaternario de la zona de cabo de Peñas (Asturias). Memoria de Licenciatura, Universidad Complutense de Madrid, Madrid.

1987 Upper Pleistocene and Holocene marine levels on the Cornisa Cantábrica (Asturias, Cantabria and Basque Country) Spain. en ZAZO, C. (ed) Late Quaternary sea-level changes in Spain. Trabajos sobre Neogeno-Cuaternario no 10 Museo Nacional de Ciencias Naturales: 251-258.

1989 La cornisa cantábrica. Mapa del Cuaternario. Ed. ITGME: 105-118

\section{JORDÁ CERDÁ, F.}

1967 La España de los tiempos paleolíticos. Raíces de España Instituto Español de Antropología Aplicada: 6-7.

1975 Notas sobre el Asturiense. Paleolítico Hispano. Las Ciencias XI (42).

1977 La Prehistoria. En Historia de Asturias ed. Ayalga.

\section{LAPLACE, G. y SAÉNZ DE BURUAGA, A.}

2000 Application de la Typologie Analytique et structuraleà l'étude de l'outillage Mousteroïde de L'Abri Olha 2 à Cambo (Kambo) en Pays Basque. Paléo, 12: 261-324.

2003 Typologie analytique et structurale des complexes du mustérien de la Grotte Gatzarria (Ossas-Suhare, Pays Basque) et leurs relations avec ceux de l'Abri Olha 2 (Cambo, Pays Basque). Pyrenae, 33-34: 81-163

\section{LAZUÉN, T., FÁBREGAS, R., LOMBERA, A. y RODRÍGUEZ, X. P.}

2011 La gestión del utillaje de piedra tallada en el Paleolítico medio de Galicia. El nivel 3 de Cova Eirós (Triacastela, Lugo). Trabajos de Prehistoria, 68 (2): 237-258.

LLOPIS, N.

1962 Mapa Geológico de Asturias. Hoja n 1 y 2. Estudio de la región del Cabo de Peñas. IDEA e IGME, Oviedo.

MÁRQUEZ, B.; MOSQUERA, M.; PANERA, J.; BÁREZ, S.; RUS, I.; GÓMEZ, J.; ARSUAGA, J. L.; PÉREZ-GONZÁLEZ, A.; BAQUEDANO, E.

2008 El poblamiento humano antiguo en el valle alto del Lozoya (Madrid). Espacio, Tiempo y Forma. Serie 1. Nueva época. Prehistoria y Arqueología, 1: 25-32.

MARTÍN BLANCO, P., MONTES BARQUÍN, R. y SANGUINO GONZÁLEZ, J.

2006 La tecnología lítica del Musteriense final en la región cantábrica: los datos de Covalejos (Velo de Piélagos, Cantabria, España). En CABRERA, V; BERNALDO DE QUIROS F; MAÍLLO, J. M. (eds): En el centenario de la cueva de El Castillo: El ocaso de los Neandertales: 231-248.
MAZO, C., UTRILLA, P., BLASCO, F., MANDADO, J., TORRES, T., ORTIZ, E. y RINK, W. J.

2011-12 El nivel musteriense de la cueva de Abauntz (Arraitz, Navarra) y su aportación al debate "vasconiense". Mainaké XXXIII: $187-214$

MONTES BARQUIIN, R.

2003 El primer poblamiento de la Región cantábrica. El Paleolítico inferior cantábrico. Museo Nacional y Centro de Investigación de Altamira, $n^{\circ}$ 18. Ministerio de Educación, Cultura y Deporte. Madrid.

PERESANI. M. (ed.).

2003 Discoid Lithic Technology. Advances and implications. Oxford: BAR Int Series, 1120

PÉREZ GONZÁLEZ, A., RUBIO, S., PANERA, J. Y URIBELARREA, D.

2008 Geocronología de la sucesión arqueoestratigráfica de Los Estragales en la Terraza Compleja de Butarque (Valle del Río Manzanares, Madrid). Geogaceta, 45 : 39-42.

\section{PÉREZ PÉREZ, M.}

1975 Los yacimientos prehistóricos de la región de Cabo Peñas. XIII Congreso Nacional de Arqueología: 109-118.

\section{RÍOS GARAIZAR, J.}

2008 Variabilidad tecnológica en el Paleolítico medio de los Pirineos occidentales: una expresión de las dinámicas históricas de las sociedades neandertales. Treballs d'arqueologia, 14: 171-194.

RIOS GARAIZAR. J., GARATE, D., GOMEZ OLIVENCIA, A., IRIARTE AVILES, E ARAMBURU, A ARCEDILLO D GARCIA A., IRIARTE CHIAPUSSO, M. J., MORENO, J., MURELAGA, X., ORTIZ, J. E. TORRES, T., SAN PEDRO, Z. y ZAPATA, L.

2011 The Lower to Middle Palaeolithic transition in Northern Iberia: new data from Arlanpe cave. Antiquity vol 085, Issue 329.

\section{RODRÍGUEZ ASENSIO, J. A.}

1978a Nota preliminar sobre las excavaciones del yacimiento de Bañugues (Gozón. Asturias). Boletín del Instituto de Estudios Asturianos, 93-94: 357-368.

1978b The Early Paleolithic site of Bañugues (Gozón. Asturias. Spain). Current Anthropology, 19 (3): 615-616.

1980 Bañugues (Gozón. Asturias). Yacimiento del Paleolítico Inferior. Noticiario Arqueológico Hispánico, 9: 11-31.

1983 La presencia humana más antigua en Asturias. Estudios de Arqueología Asturiana, $\mathrm{n}^{\circ}$ 2. Oviedo.

1990 Los orígenes del poblamiento en Asturias: El Paleolítico Inferior y Medio. Historia de Asturias T.I. ed. Prensa asturiana: 33-48.

2000 El Paleolítico antiguo en Asturias. SPAL 9. Homenaje al prof. Vallespí: 109-123.

\section{RODRÍGUEZ ASENSIO, J.A. y ARRIZABALAGA, A.}

2004 El poblamiento más antiguo de la región: las ocupaciones previas al IS4. Desde el inicio del poblamiento a circa 80.000 BP. En FANO, M. (coor): Las sociedades del Paleolítico en la región cantábrica. KOBIE (Serie Anejos), 8: 51-90. 
RODRÍGUEZ ASENSIO, J. A. y FLOR G.

1980 Estudio del yacimiento prehistórico de Bañugues y su medio de depósito (Gozón, Asturias). Zephyrus, XXX-XXI: 205-222.

1983 Industrias paleolíticas eolizadas en la región del Cabo Peñas. Cuadernos del Laboratorio Xeolóxico de Laxe, 5: 23-46.

\section{RODRÍGUEZ ASENSIO, J.A; NOVAL FONSECA, M.A.}

1980 Gijón antes de Gijón. Breve aproximación a los primeros grupos predadores en la prehistoria asturiana, Gran enciclopedia asturiana, Gijón

SÁNCHEZ YUSTOS, P., DÍEZ MARTÍN, F., DÍAZ MUÑOZ, M. I., GÓMEZ DE LA RÚA, D. y GÓMEZ GONZÁLEZ, J. A.

2011 Estrategias de talla en Cueva Corazón (Mave, Palencia). Un yacimiento del Musteriense antiguo en las estribaciones meridionales de la Cordillera Cantábrica. Trabajos de Prehistoria, 68 (1): 51-63.

SANTAMARÍA, D., RASILLA, M. de la, MARTÍNEZ, L. y TARRIÑO, A.

2011 Las herramientas y su interpretación cultural y económica. En RASILLA, M. DE LA, ROSAS, A. CAÑAVERAS, J.C. Y LALUEZA, C. (eds.): La cueva de El Sidrón (Borines, Piloña, Asturias). Investigación interdisciplinar de un grupo neandertal, ed. Trea / Principado de Asturias: 137-146.

\section{SANTONJA, M.}

1991-92 Los últimos diez años de investigación del Paleolítico inferior de la cuenca del Duero. Veleia, 8-9: 7-41.

\section{SANTONJA GÓMEZ, M. y PÉREZ GONZÁLEZ, A.}

2006 La industria lítica del miembro estratigráfico medio de Ambrona (Soria, España) en el contexto del Paleolítico antiguo de la Península Ibérica. Zephyrus, LIX: 7-20

2010a Mid-Pleistocene Acheulean industrial complex in the lberian Peninsula. Quaternary International, 223-224: 154-161.

2010b Precisiones en torno a la edad y la industria lítica de El Aculadero (El Puerto de Santa María, Cádiz). Cuaternario y Arqueología. Homenaje a Francisco Giles Pacheco: 19-26.

SLIMAK, L.

2003 Les debitages discoïdes mousteriens: evaloation d'un concept technologique. En: PERESANI. M. (ed.). Discoid Lithic Technology. Advances and implications. Oxford: BAR Int Series, 1120: 33-65.

SORESSI, M.

2002 Le Moustérien de tradition acheuléenne du sud-ouest de la France. Discussion sur la signification du faciès à partir de l'étude comparée de quatre sites: Pech-de-l'Azé I, Le Moustier, La Rochette et la Grotte XVI. Thèse de I'Université Bordeaux I, $339 \mathrm{p}$.

TAPIA, J.

2010 El depósito paleolítico de La Garma A: estratigrafía y aproximación taxonómica, Trabajo de Investigación de 3er ciclo, Departamento de Ciencias Históricas, Universidad de Cantabria (inédito).

TERRADAS, $X$.

2003 Discoid flaking method: conception and technological variability. En: PERESANI, M. (ed.). Discoid Lithic Technology. Advances and Implications. Oxford: BAR Int.Series, 1120: 19-31.
TIXIER, J.

1956 Le hachereau dans l'Acheuléen nord-africain. Notes typologiques. Congrès Préhistorique de la France XVe Session. Poitiers-Angoulême: 914-923.

TORRE, I. de la, MARTÍNEZ MORENO, J. y MORA, R.

2013 Change the stats in the Iberian Middle Palaeolithic: Considerations on the significance of Mousterian technological variability. Current Anthropology, 54(58): 320-336.

TURQ, A.

2000 Le Moustérien de tradition acheuléenne. Paléo, supplément: 244-273.

TURQ, A., BRENET, M., COLOGNE, D., JARRY, M. LELOUVIER, LA., O'FARREL, M. y JAUBERT, J.

2010 The first occupations in Southwestern France: A revised summary twenty years alter the Abbeville/Saint Riquier coIloquium. Quaternary International, 223-224: 383-398.

VEGA, L. G., COSANO, P., VILLAR, A., ESCARPA, O. y ROJAS, T.

1997 Las industrias de la interfase Pleistoceno Medio - Superior en la cueva de la Carihuela (Piñar, Granada). I/ Congreso de Arqueología Peninsular. Vol. I: Paleolítico y Epipaleolítico. Zamora: 105-119. 